\title{
The Role of Mindfulness in Mitigating the Negative Consequences of Technostress
}

\author{
Athina loannou ${ }^{1}$ (D) Mark Lycett $^{2} \cdot$ Alaa Marshan $^{3}$ \\ Accepted: 18 December 2021 \\ (c) The Author(s), under exclusive licence to Springer Science+Business Media, LLC, part of Springer Nature 2022
}

\begin{abstract}
IT offers significant benefits both to individuals and organisations, such as during the Covid-19 pandemic where technology played a primary role in aiding remote working environments; however, IT use comes with consequences such as 'technostress' - stress arising from extended use of technology. Addressing the paucity of research related to this topic, in this study, we examine the role of mindfulness and IT mindfulness to both mitigate the impact of technostress and alleviate its negative consequences; revealing that mindfulness can reduce technostress and increase job satisfaction, while IT mindfulness can enhance user satisfaction and improve task performance. Moreover, our work sheds light on the under-researched relationship between mindfulness and IT mindfulness; showing that the latter has a stronger influence on IT related outcomes; revealing the valuable role of mindfulness and IT mindfulness in the workplace and offering important implications to theory and practice.
\end{abstract}

Keywords Mindfulness $\cdot$ Technostress $\cdot$ Performance $\cdot$ Cluster analysis $\cdot$ Organisational settings

\section{Introduction}

Information Technology (IT) has been characterized as a double edged sword (Liang \& Xue, 2009) as, while it offers considerable benefits, it also poses challenges. The proliferation of IT within organisations has led to tremendous improvements in their performance and efficiency; however, there are negative aspects related to stress caused by IT (Fischer \& Riedl, 2017; Tarafdar et al., 2017). This so-called 'technostress' refers to the stress experienced by individuals in organisations due to the extended use of information technology. Symptoms of technostress include fatigue, inability to concentrate, frustration, loss of motivation, dissatisfaction at work, reduced productivity and burnout (Ragu-Nathan et al., 2008).

Athina Ioannou

a.ioannou@surrey.ac.uk

Surrey Business School, University of Surrey, Guildford, UK

2 School of Management, Royal Holloway, University of London, London, UK

3 Department of Computer Science, Brunel University London, Uxbridge, UK
Technostress experiences occur daily at work as well as during times of crises accompanied by detrimental effects for employees. A very recent prominent example constitutes the current on-going Covid-19 pandemic where technology has been playing a significant role in aiding remote working environments; however, the ability to work from home and the extensive use of technology also caused negative consequences affecting psychological well-being of employees and increasing technostress experiences (Carroll \& Conboy, 2020; Dey et al., 2020; Molino et al., 2020; Prasad et al., 2020). Experiences of technology failure incidents (i.e., technology crises) such as errors, breakdowns, disruptions and delays (e.g., failed network connections, missing features, unexpected shutdowns and crashes in applications and systems) can also trigger technostress feelings at work decreasing employee performance by almost 30\% (Huling, 2020). Employees who experience such stressful situations feel twice as stressed and take three times longer to recover (Huling, 2020).

Overall, the bottom-line effects of technostress are significant - it is estimated that workplace stress costs more than 100 billion pounds every year to UK businesses due to decreased employee productivity and increased absenteeism, turnover and insurance costs (MAPPG, 2015). Given that technostress has a clear impact on business performance and 
potentially the overall success of organisations, measures need to be taken in order to mitigate this phenomenon.

Organisational mechanisms such as literacy facilitation, technical support and involvement facilitation have been suggested as means that can reduce the impact of technostress on individuals (Ragu-Nathan et al., 2008; Tarafdar et al., 2010). These mechanisms, often called technostress inhibitors, have become the main focus of extant studies in the IS literature - however, the problem continues to exist today (Dey et al., 2020; Molino et al., 2020). There is a paucity of research exploring alternative/further means that could alleviate the adverse aftereffects of technostress. As a pointer here, research has suggested that mindfulness can act as a potential mechanism to alleviate workplace stress (MAPPG, 2015). Although previous studies have extensively investigated the beneficial effects of mindfulness on work related stress in general, there is little research concentrating on the relationship between mindfulness and technostress (Ioannou \& Papazafeiropoulou, 2017; Pflügner et al., 2021). This is perhaps unsurprising as, according to a recent review of mindfulness in the IS domain, the research area is still in its early stages (Dernbecher \& Beck, 2017; Tarafdar et al., 2017). The research that does exist focuses on the negative impact of technostress on individual organisational factors, such as user performance, but fails to explore the potential beneficial influence of mindfulness as a counterbalance to the negative effects of technostress. Mindfulness can offer significant advantages in the workplace such as enhancing individual performance and work resilience while also reducing absenteeism and turnover (Hyland et al., 2015). As the state-of-the-art stands, however, empirical evidence remains scarce (Good et al., 2016; Mesmer-Magnus et al., 2017). Consequently, we focus here on investigating the effects of dispositional mindfulness (referred to as mindfulness in the rest of the manuscript) as well as IT mindfulness on technostress and their negative consequences that arise within the workplace aiming to demonstrate their beneficial and protective role against technostress. We do so using structural equation modelling as the main data analysis technique to examine whether employees' tendencies to be mindful are linked with perceptions of technostress alongside levels of user satisfaction and performance while using IT for daily work tasks. Then, we conduct cluster analysis to get more insights into how different groups of participants form based on their mindfulness and IT mindfulness characteristics. Thus, we examine the role of mindfulness and IT mindfulness that can mitigate the negative consequences of technostress within workplace settings. The research question of the study is formulated as 'What are the effects of mindfulness and IT mindfulness on technostress and its negative consequences within the workplace?'

This paper is structured as follows. First a theoretical background of the concepts of Technostress and Mindfulness is provided to delineate the relationship between them. Second, a theoretical model is developed from the extant literature alongside a set of hypotheses that are subsequently used to assess that model. Third, a detailed description of our methodology including the survey instrument used for data collection is described. Fourth, the results from the descriptive data analysis and hypotheses testing are presented. Finally, the discussion section presents a detailed discussion of our findings and conclusions along with the results of extant literature and offering some suggestions for future research.

\section{Theoretical Background}

The following sub-sections introduce the theoretical base of the current research study. We provide an overview of existing research on technostress, highlighting its impact on work related outcomes within organisational settings. In addition, we offer a thorough overview of current research on mindfulness within the IS domain, presenting the concept of 'IT mindfulness'.

\subsection{Technostress}

Organisational stress has been a central area of interest in the academic literature for decades, as it constitutes an important mediator of business performance and overall success. Recently, a significant volume of published studies has been focusing on the stress caused by IT in the work environment: This 'technostress' was defined for the first time in 1984 by clinical psychologist (Brod, 1984, p. 16) as "a modern disease of adaptation caused by an inability to cope with new computer technologies in a healthy manner" and, more recently, as "any negative impact on attitudes, thoughts, behaviors or psychology caused directly or indirectly by technology" (Weil \& Rosen, 1997, p. 36).

In the IS domain, a considerable amount of research has been published on the concept of technostress (Tarafdar et al., 2013). In their seminal paper, Ragu-Nathan et al. (2008) empirically validated five factors that create technostress, classifying them as: (1) techno overload, which describes situations where IT forces individuals to work faster and longer; (2) techno invasion, which refers to situations where the individual feels 'always connected' and can be reached anywhere and anytime; (3) techno insecurity, which describes situations where individuals feel threatened that they will lose their job either to other people who are more capable with new IT, or being replaced by new information systems (Stich et al., 2019; Tarafdar et al., 2010); (4) techno uncertainty, which indicates contexts where individuals feel unsettled due to the constant changes and upgrades of technologies inside the organisational workplace; and (5) 
techno complexity, which refers to situations where individuals feel inadequate in terms of technology skills due to the perceived complexity of newly introduced IT within the workplace (Tarafdar et al., 2010).

The consequences of technostress can manifest not only in behavioral ways, such as poor productivity, decreased performance and turnover intention; but also, in psychological ways, such as job dissatisfaction and depression (Tarafdar et al., 2010), and physiological effects such as elevated levels of cortisol (Riedl et al., 2012). Evidence has shown that technostress severely affects numerous work related outcomes such as job satisfaction, productivity, turnover intention and organisational commitment (Ayyagari et al., 2011; Ragu-Nathan et al., 2008; Tarafdar et al., 2007, 2010, 2015). Studies examining factors that can alleviate the negative consequences of technostress are in a minority, though organisational mechanisms such as literacy facilitation, technical support and involvement facilitation have been proposed as means that can alleviate technostress on individuals (Ragu-Nathan et al., 2008; Tarafdar et al., 2010). Unsurprisingly, there are clear calls for further research to identify (potentially) more effective means that can mitigate the negative after effects of technostress (D'Arcy et al., 2014; Hung et al., 2011; Weinert, 2018).

\subsection{Mindfulness and its Application to IT}

Mindfulness is one such means that can potentially alleviate the adverse consequences of technostress - a concept initially introduced in psychology and the health sector as an attempt to discover alternative practices to alleviate medical and psychological health issues (a Chiesa \& Serretti, 2009). Research findings indicate that mindfulness practices offer a myriad of benefits to individuals such as lower levels of stress and anxiety, enhanced well-being (A. Chiesa \& Serretti, 2010), improved working memory and increased emotional intelligence (Brown et al., 2007). Mindfulness is described as a "state of conscious awareness in which the individual is implicitly aware of the context and content of information" (Langer, 1992, p. 289). It is a dynamic and rich state of awareness and alertness along with a heightened state of involvement (Langer, 1989, 2000). It incorporates the idea of being in the present moment rather than focusing on past experiences and future plans. Scientific research has adapted several different perspectives on mindfulness and has depicted it as a state, a dispositional trait, an attitude, a cognitive process, a type of meditation and an intervention program (Choi \& Leroy, 2015). Dispositional mindfulness, also known as trait mindfulness, is the focus of the present study. Dispositional mindfulness is malleable and can be enhanced and cultivated through training and interventions programs (Ioannou et al., 2021; Quaglia et al., 2016).
In the Information Systems (IS) domain, mindfulness was firstly introduced through the work of Ramiller and Swanson (2009), which proposed the idea of incorporating it into the processes of IT innovation in an organisation. Several research studies followed, mostly focusing on the organisational or collective level (Aanestad \& Jensen, 2016; Amaye et al., 2016; Butler \& Gray, 2006; Carlo et al., 2012; Teo et al., 2011). It is only recently that studies have emerged focusing on the individual level of mindfulness (Bernárdez et al., 2018; Jensen et al., 2017; Maier et al., 2017; Sun et al., 2016; Zou et al., 2015). Individual-level studies extend the notion in the IT systems use context, investigating the influences of mindfulness on technology adoption decisions (Sun, 2011; Sun et al., 2016) as well as on the use of e-government systems (Hadidi \& Carter, 2016). Despite wide adoption of the concept, however, there is a notable lack of research developing a domain specific instrument for the assessment of individual mindfulness (Roberts et al., 2007a; Sun, 2011).

Recently, work has addressed this issue by systematically developing the concept of IT mindfulness, Thatcher et al. (2018, p. 5) defining it as "a dynamic IT-specific trait, evident [only] when [an individual is] working with IT.". Grounded on Langer's definition, Thatcher et al. (2018) argue that IT mindfulness, oriented toward the use of IT and its contexts, consists of four dimensions: (1) alertness to distinction, which refers to the extent that an IT mindful individual understands the capabilities of IT applications and the context that they will prove more useful; (2) awareness of multiple perspectives, which refers to the IT mindful individual who is able to identify multiple uses of a specific IT application as well as develop innovative solutions to emerging problems (Roberts et al., 2007a; Thatcher et al., 2018); (3) openness to novelty, which refers to the willingness of an individual to explore more potential and novel applications of the deployed system; and (4) orientation in the present, which refers to the IT mindful individual who is focused on the present moment and context thus able to adapt technologies to several different contexts (Roberts et al., 2007a).

\subsection{Mindfulness \& Technostress}

The present study aims to examine the role of mindfulness in reducing technostress conditions within the workplace. Past literature has sought to bring the stress and mindfulness concepts together. Studies have examined the effectiveness of mindfulness in decreasing workplace stress (Grégoire \& Lachance, 2015; Shapiro et al., 2015; E. Shonin \& Van Gordon, 2015; Van Gordon et al., 2014). Additionally, studies have examined the positive effect of mindfulness on employee well-being, which is associated with a number of work related aspects such as productivity, performance, 
turnover intention and absenteeism (Dane, 2013; Glomb et al., 2011; Good et al., 2016; Schultz et al., 2015). As the state-of-the-art stands, however, there is little research that concentrates on the relationship between mindfulness and technostress (Pflügner et al., 2021) and scholars have argued that further research is essential in the area, emphasising that coping responses, emotions or actions to deal with the perceived threat have been under researched (see (Tarafdar et al., 2017). The limited evidence base that does exist, indicates that mindfulness lessens job burnout through technostress in white-collar workers (Pflügner et al., 2021), while IT mindfulness, oriented toward IT use and its contexts, reduces perceptions of technostress (Ioannou \& Papazafeiropoulou, 2017). Since the conceptualisation of IT mindfulness in the IS domain as a theoretical construct (Roberts et al., 2007b; Thatcher et al., 2018), however, there have been no practical advancements in developing guidelines or programmes that can cultivate and enhance IT mindfulness. In addition, prior research on IT mindfulness and technostress has compared the impact of mindfulness on technostressors with other IS context specific traits (e.g., personal innovativeness in IT) - neglecting the role of mindfulness, as a generic, broad trait that might influence technostress conditions in the workplace (Thatcher et al., 2018). Consequently, there is a need for additional studies exploring the role of mindfulness as a potential alleviator to stress induced by extended IT usage.

\section{Model and Hypotheses}

In addressing this challenge, we propose a theoretical model grounded on the extant body of technostress literature and the transaction theory of stress (Lazarus, 1966; Lazarus \& Folkman, 1984), which the majority of studies in technostress literature use (Tarafdar et al., 2017). This model (shown in Fig. 1) theorises that stress resides neither in the individual nor in the environment but, rather, in the relationship between them (Fuglseth \& Sørebø, 2014; Lee et al., 2016; Ragu-Nathan et al., 2008). The transaction-based approach describes stress as "a combination of a stimulation condition and the individual's response to it" (Ragu-Nathan et al., 2008, p. 419); this ongoing transactional process, where the demands of the environment exceed the person's capabilities, is referred to as stress (Cooper et al., 2001; Fieseler et al., 2014; Fuglseth \& Sørebø, 2014). The model of this approach consists of four major components:: (1) stressors, which are the events, stimuli or conditions that create stress; (2) situational factors, that describe organizational mechanisms that can buffer or reduce the impact of stressors; (3) strain outcomes, referring to the behavioural and psychological outcomes of stress observed in individuals including responses with high levels of exhaustion, discomfort and dissatisfaction; and/or (4) other organizational outcomes that can be work related outcomes such as turnover intention or absenteeism that are influenced by strain (Cooper et al., 2001).

We build on this model by focusing on technostress stressors, mindfulness and IT mindfulness as situational factors drawing on previous technostress literature focusing on IT organisational environments (Fuglseth \& Søreb $\varnothing$, 2014). Drawing on earlier observations, our proposed model incorporates both mindfulness and IT mindfulness as situational variables (technostress inhibitors) that can reduce the effects of technostress on individuals within organisational settings (Tarafdar et al., 2007). Doing this not only addresses the noted calls for research in the literature but also allows us to examine the potential buffering roles of mindfulness and IT mindfulness as, for example, there may be differential impact of technostressors and/or different effects arising from extended IT usage within organizational settings. We also focus on certain organisational outcomes such as job satisfaction, end user satisfaction and end user performance. User satisfaction and performance constitute critical factors affecting the overall success and profitability of an
Fig. 1 Transaction theory of stress

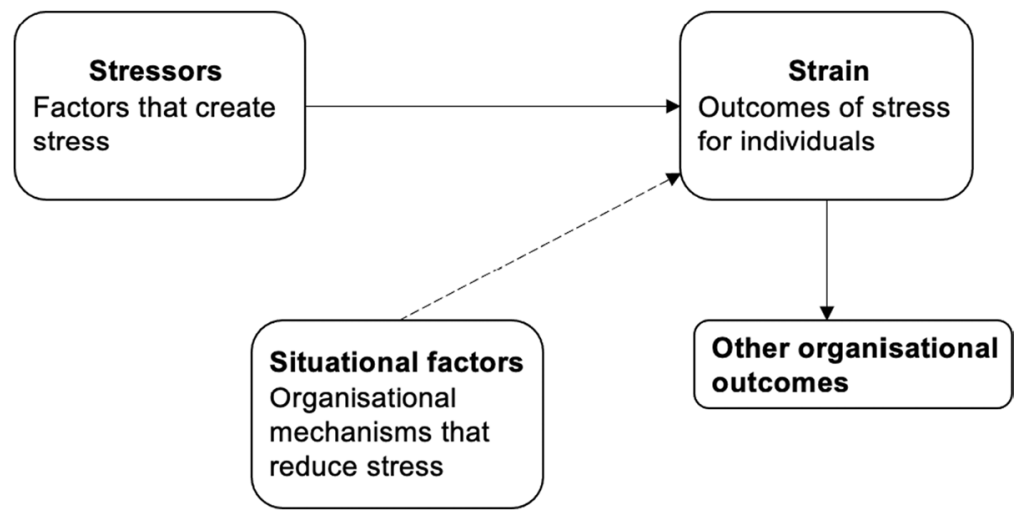


organisation; given the size of investments in information technology (IT), companies are primarily concerned with its impact on individual productivity and organisational profitability using user satisfaction as a surrogate for a system's effectiveness and overall success (DeLone \& McLean, 1992; Hou, 2012; Tarafdar et al., 2010) and user performance as a measure for the assessment of the business benefits accruing from the deployed IT. The majority of past studies have focused on the investigation of the impact of technostress on behavioural and psychological outcomes such as job dissatisfaction and depression (Tarafdar et al., 2010); while studies incorporating the category of strain of the end user computing perspective are scarce (Tarafdar et al., 2010). As a result, in this study we focus on the end user perspective, including both end user performance and end user satisfaction as indicators. We also focus on the work related outcome of job satisfaction, which can affect the productivity of an individual as well his performance, motivation, organisational commitment and rates of absenteeism (Khan et al., 2012). Widely studied in the stress and technostress literature, job satisfaction can severely affect employee functioning and thus create substantial costs for organisations (Ragu-Nathan et al., 2008).

Overall, the proposed theoretical model of the current study (see Fig. 2) is based on the transaction-based model of stress and examines the roles of mindfulness and IT mindfulness that can reduce the effects of technostress on individuals within organizational settings (Tarafdar et al., 2007) as well as improve organisational outcomes (i.e., end user satisfaction, end user performance, job satisfaction).

\subsection{Research Hypotheses}

Previous empirical research has shown that technostress can significantly decrease an individual's job satisfaction (Fieseler et al., 2014; Jena, 2015; Khan \& Rehman, 2013; Kumar et al., 2013; Ragu-Nathan et al., 2008) and user satisfaction (Tarafdar et al., 2010). IT has radically changed the conventional workday and employees can be reached anytime and anywhere through technology (techno invasion). Having imposed a new working environment, mobile devices force employees to work faster and longer by simultaneously utilizing several sources of information in order to complete their work tasks (techno overload) (Tarafdar et al., 2011). Employees therefore need to spend more time and effort updating their skills and knowledge in order to keep up with constantly evolving IT changes and implementations (Chandra et al., 2015), while potentially feeling threatened that they might lose their job to people more technologically equipped. As a result, individuals experience tension and stress, thus developing a negative attitude towards their job and IT software they are using, feeling dissatisfied both with their work environment and IT applications at hand (Ragu-Nathan et al., 2008; Tarafdar et al., 2011). Based on the above arguments, the following hypotheses are framed:

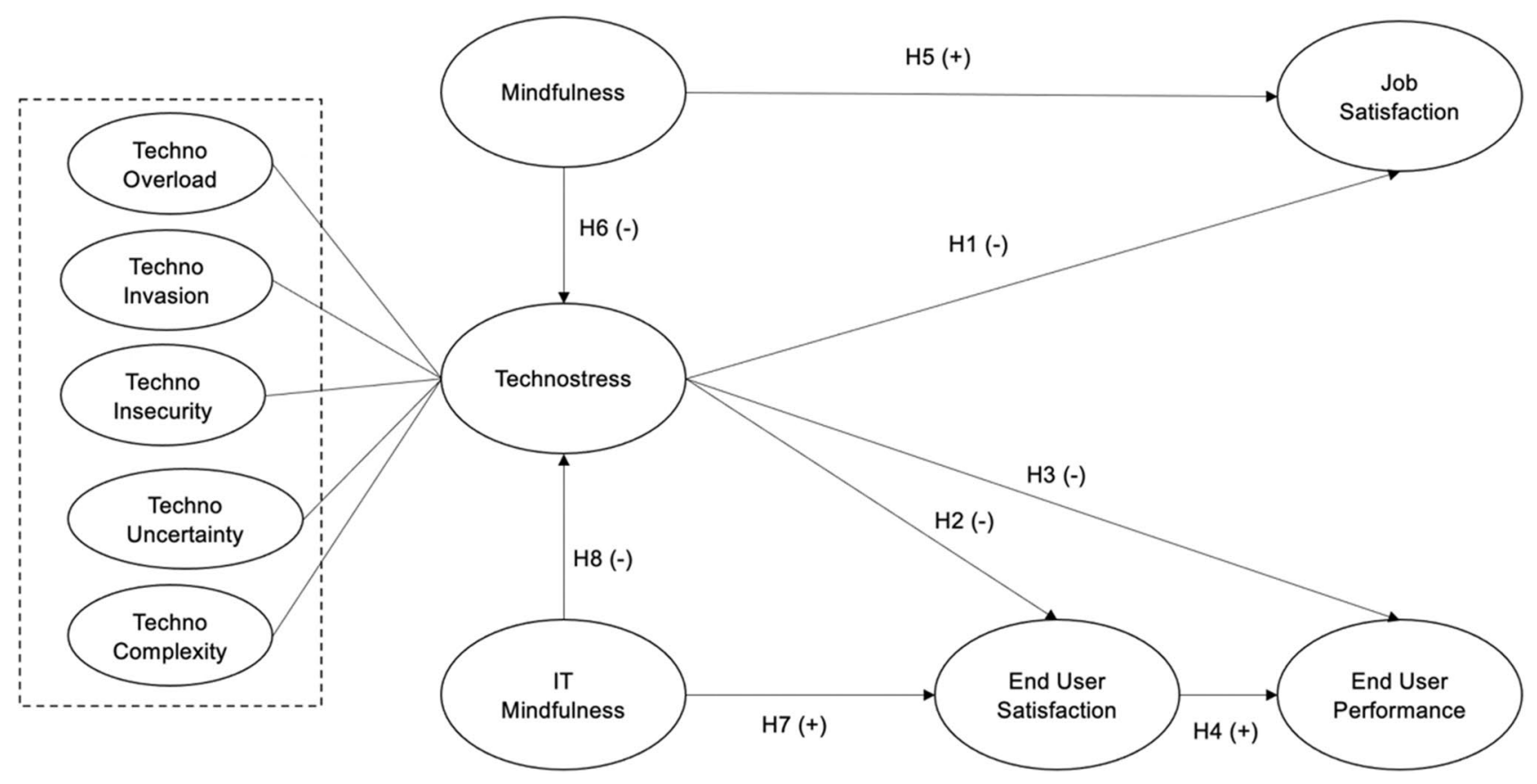

Fig. 2 Proposed theoretical framework of mindfulness and technostress 
H1: Technostress creators are negatively associated with job satisfaction

$\mathrm{H} 2$ : Technostress creators are negatively associated with end user satisfaction

Previous studies have conclusively shown that technostress can significantly undermine an employee's performance when utilizing IT for work tasks (Chen \& Muthitacharoen, 2016). Excessive multitasking, alongside interruptions, significantly affect the effectiveness of an individual within work settings (Levy et al., 2012; Tarafdar et al., 2010). Moreover, employees who resist learning new technologies encounter numerous errors and failures with the system and experience frustration, thus leading to reduced performance (Tarafdar et al., 2010). Additionally, due to techno complexity, individuals need to spend more time and effort in understanding new IT applications, which leaves little time to devote to more productive and creative work tasks. Hence, end user performance is considerably decreased (Tarafdar et al., 2015). Based on the above arguments the third hypothesis is framed as:

H3: Technostress creators are negatively associated with end user performance

Previous studies have conclusively shown that user satisfaction has a strong positive effect on individual performance in terms of productivity and task innovation within organisational settings (Hou, 2012; Hsu et al., 2008; Tarafdar et al., 2010). More specifically, individuals that are satisfied with the IT applications they use at work manage to process information more effectively, thus improving the quality of their work. In addition, employees satisfied with the deployed IT applications have more free time and are more willing to explore additional functions of an application as well as search for more efficient ways to execute work processes, thus becoming more creative and innovative (Tarafdar et al., 2010). Based on the above arguments the fourth hypothesis is framed as:

H4: End user satisfaction is positively associated with end user performance

Though there is very little published research on the investigation of the relationship between mindfulness and job satisfaction, evidence has shown that the two constructs are positively related (Hülsheger et al., 2012; Reb et al., 2015; Edo Shonin et al., 2014). A more mindful individual is able to distance himself from stressful events and experiences, as well as from stressful thoughts and emotions; thus they are more likely to observe stressful situations that occur at work more objectively, perceive both stressful events and stressors as less threatening and thus express less negative and more positive reactions (Good et al., 2016; Schultz et al., 2015). Hence, the individual evaluates his job in a more positive way leading to increased job satisfaction (Hülsheger et al., 2012). Based on the above arguments, the fifth hypothesis is framed as:

H5: Mindfulness is positively related to job satisfaction.

Mindfulness fosters more effective stress processing (Weinstein et al., 2009) by directly reducing work stress (Grover et al., 2016) while recent evidence also suggests that mindfulness results in lower levels of perceived technostress (Pflügner et al., 2021). A more mindful individual can cope more effectively with stressful situations by choosing fewer avoidance strategies and more adaptive ways of coping (Weinstein et al., 2009). Previous studies have shown that mindfulness can mitigate the negative consequences arising from information overload (Wolf et al., 2011) and multitasking (Levy et al., 2012) thus decreasing techno overload. Moreover, by thoughtfully considering how to react to IT interruptions, such as emails arising outside of work settings, a more mindful individual is more likely to appraise these situations as less threatening and respond more objectively thus decreasing the impact of techno invasion (Alberts \& Hülsheger, 2015; Schultz et al., 2015). In fully experiencing a situation, a more mindful individual can combat feelings of anxiety and stress about the future that arise from job insecurity (Glomb et al., 2011; Jacobs \& Blustein, 2008) thus decreasing techno insecurity. Also, more mindful individuals feel more confident about their skills and become more interested in enhancing their learning efforts towards combatting the unsettling feelings and uncertainty caused both by techno complexity and techno uncertainty (Glomb et al., 2011). As a result, overall based on the above arguments the following hypothesis is framed:

H6: Mindfulness negatively associated with technostress creators

Previous studies have empirically demonstrated that IT mindfulness can positively affect user satisfaction at the post-adoption phase of a system (Sun, 2011) while also having a positive impact on task-technology fit, which leads to higher user satisfaction and intention to use the system (Sun et al., 2016). A more IT mindful individual will respond in a more flexible and adaptive way to unexpected events and technology incidents occurring in his working environment, thus resulting in higher end user satisfaction (Sun, 2011). Furthermore, a more IT mindful individual is able to vary their response and shift perspectives depending on the context, creating innovative solutions to resolve problems and technology failures that require a fit between the deployed technology and the task at hand (Carson \& Langer, 2006; 
Langer \& Moldoveanu, 2000; Roberts et al., 2007b). As a result, they are able to complete IT-mediated tasks successfully, experiencing more positive feelings and less negative attitude towards the IT in use. Based on the above arguments, we frame the following hypothesis as:

H7: IT Mindfulness is positively related to end user satisfaction

Recently it has been empirically shown that IT mindfulness can decrease the impact of technostress that arises within the workplace (Ioannou \& Papazafeiropoulou, 2017; Maier et al., 2019). A more IT mindful user is able to consider alternative perspectives when a problem occurs as well as implement 'workarounds' in order to execute his work processes (Roberts et al., 2007b) thus the impact of techno overload is decreased. Oriented toward the present, an IT mindful user is able to adapt their IT application uses depending on the specific context (Thatcher et al., 2018). As a result, the user is able to vary their response to incoming interruptions by adapting to the current environment and consciously understanding alternative choices such as deciding to avoid using a mobile device when at home (Ragu-Nathan et al., 2008), thus decreasing the impact of techno invasion. Open to novel stimuli and new information, a more IT mindful user demonstrates curiosity in exploring existing and new features of IT applications, thus reducing the perceived complexity of the deployed IT (Langer, 1989; Thatcher et al., 2018) (techno complexity and techno uncertainty). Last, a more IT mindful individual can decrease his feelings of job insecurity (techno insecurity) by acknowledging that the same situation or stimulus when called by a different name or interpreted differently is a different stimulus (Langer, 1989). Based on the previous arguments the following hypothesis can be formed:

H8: IT Mindfulness is negatively associated with technostress creators

\section{Research Method}

In testing our framework and associated hypotheses, we adopted a survey-based approach for data collection - primarily as our aim was to extract information and explore several industries, sectors and people from different backgrounds that would provide deep insights and richness to our results. Data analysis was conducted using Structural Equation Modeling (SEM), since our proposed theoretical model is rather sophisticated and requires the testing of a series of interrelated dependence relationships that is not feasible with other statistical methods. SEM was used to evaluate our model as a whole, testing our proposed hypotheses examining the effects of mindfulness and IT mindfulness on technostress and its negative consequences. Further exploring the investigated sample, we perform cluster analysis aiming to investigate whether employee tendencies to be mindful and/or IT mindful are linked with differences in perceptions of technostress as well as different levels of the outcome variables. By employing cluster analysis, we are adding additional depth to our analysis, aiming to reveal more insights from the profiles of individuals in the collected data that have not been uncovered previously.

\subsection{Survey Instrument}

The survey instrument (see Table 18 in Appendix A) consists of fifty-nine items measuring the six main constructs. Previously established scales were used (adopted from existing literature), whose validity and reliability has been proven in several contexts and populations prior to this research (Bhattacherjee, 2001; Brown \& Ryan, 2003; Tarafdar et al., 2007, 2010; Thatcher et al., 2018). For the construct of IT mindfulness the short version of the adopted instrument was already established in terms of discriminant and convergent validity by previous works (Thatcher et al., 2018), for purposes of brevity, including reduction of completion time and increase in participation rates, conforming with contemporary psychology research practices (Smith et al., 2012). In accordance with the existing base of technostress research, technostress and end user performance were modelled as a second order constructs (Pflügner et al., 2021; Tarafdar et al., 2015). Mindfulness was also modelled as a second order construct following practices in existing mindfulness research (Kiken \& Shook, 2012; Pearson et al., 2015). Appendix B provides a detail description of the conceptualisation of the second order constructs. All items in the questionnaire were measured with a five-point Likert scale ( $1=$ strongly disagree, $5=$ strongly agree). For background information, demographic data capturing the gender, age, education, total working experience, current working experience, and daily technology usage at work were collected.

\subsection{Data Collection}

A pilot survey was first conducted with a sample of $20 \mathrm{PhD}$ students (Computer Science) to obtain feedback and make any necessary changes in the phrasing/wording of questions. The primary data was then collected by distributing an online questionnaire across several industries to knowledge workers - working individuals using IT in their day-to-day work within the UK. Convenience sampling was used for the distribution of the online survey, that was conducted via email invitations as well as posting calls for participation in professional social media networks. Overall, 500 individuals participated, providing a very good sample size for SEM. 
According to Hair et al., (2010), the minimum sample size for a study with seven or less constructs ranges from 150 to 300 while others have recommended 10 cases per indicator (variable) (Nunnally, 1978) or 5-10 cases per estimated parameter (Bentler \& Chou, 1987). In accordance with the recommendations of various seminal authors regarding the minimum required sample size for the execution of SEM analysis, the present study estimated that the latent variables (constructs) of the model are six (6) and the observed variables (indicators) twenty (20), while the parameters are estimated to be around fifty (50); suggesting that the sample size required for the current study should be minimum 300 cases. Moreover, G-power analysis, using the sempackage in $\mathrm{R}$, was also conducted showing a minimum of 161 cases required (see Appendix B for results). Overall, it was established that the acquired sample size is adequate. For analysis of the quantitative data, a preliminary examination was undertaken to detect missing data and outliers as well as test for normality, linearity, and multicollinearity. Missing data was imputed using mean substitution, such that the usable sample remained at 500 responses. SEM was then employed, using IBM SPSS AMOS, to test the hypotheses underlying our theoretical model.

\section{Results}

\subsection{Descriptive Statistics}

The survey results (see Table 17 Appendix A) showed that participants were relatively proportionally split into male $(53 \%)$ and female (47\%); most of them between the ages of 26-35 (49\%), holding a master's degree (40\%), with current working experience $1-5$ years (57\%), total working experience 6-10 years (32\%) and a daily technology usage of more than $6 \mathrm{~h}$ per day $(82 \%)$.

\subsection{Hypotheses Testing Using Structural Equation Modeling}

Data analysis comprised of two main stages. First, the measurement model was specified in order to assess the fit of the data in relation to the theoretical model and, subsequently, assess the reliability and validity of the constructs. Second, we specified the structural model in order to test the proposed hypotheses associated with the model.

\subsection{Measurement Model (CFA) and Construct Validity}

At first, Exploratory Factor Analysis was conducted in order to check the structure and loadings of the underlying factors of each construct. Furthermore, we tested for Common Method Bias (CMB) (Podsakoff et al., 2003). Next, Confirmatory Factory Analysis followed using covariance-based SEM with IBM SPSS AMOS 23. Convergent validity, discriminant validity and nomological validity were also tested. Several iterations and modifications were undertaken in the measurement model in order to achieve best fit. The sections below present the results of the analyses (see Appendix B for additional details).

\subsubsection{Exploratory Factor Analysis (EFA)}

Exploratory factor analysis with Maximum Likelihood (ML) and Promax rotation was conducted to ensure the structure of the constructs' underlying factors. As evident in Tables 1, 44 items were included in the EFA. According to Costello and Osborne (2005) a subject-to-variable ratio of 10:1 is essential, thus our ratio 11:1 establishes the reliability of the study. Results of the EFA indicate that items load well $(>=0.5)$ on their relevant constructs retaining their proposed structure. One item from the technostress scale (CO3) showed a low loading (<.49), we decided on its retention due to importance of the scale for the purposes of the study.

\subsubsection{Common Method Bias (CMB)}

Following common guidelines, we tested for common method bias (CMB) using two approaches. At first, CMB was tested in SPSS 21 with Harman's single factor test, with results indicating that there was no bias in our data $-14.32 \%$ of the variance in all variables is explained by a single factor, indicating that common method bias isn't a concern in our data collection (the single factor results for less than $50 \%$ of the total variance) (Podsakoff et al., 2003). Moreover, the common method factor technique was conducted for identifying common method variance (Bagozzi 1984; Podsakoff et al., 2003). Results of a CFA analysis in AMOS measuring all the relevant variables showed that there is $2.61 \%$ bias in our collected data. Thus, overall, our results support the conclusion that CMB is not a concern in the analysis of our study. As a result, for the rest of the analysis in this paper we proceeded without the common method factor.

\subsubsection{Construct Validity}

Convergent validity was measured by calculating the Average Variance Extracted (AVE) for each construct, which should be above 0.5 (Asyraf \& Afthanorhan, 2013). As shown in Table 2, all AVE estimates exceed that figure, except for the technostress creators construct. Convergent 
Table 1 EFA loadings

\begin{tabular}{|c|c|c|c|c|c|c|c|c|c|c|c|}
\hline & 1 & 2 & 3 & 4 & 5 & 6 & 7 & 8 & 9 & 10 & 11 \\
\hline MAAS1 & -0.071 & -0.077 & 0.002 & 0.071 & -0.001 & 0.042 & 0.008 & 0.759 & -0.018 & 0.030 & 0.027 \\
\hline MAAS2 & -0.026 & 0.103 & 0.005 & -0.013 & -0.021 & -0.024 & 0.012 & 0.902 & 0.026 & -0.020 & 0.041 \\
\hline MAAS3 & 0.082 & -0.089 & -0.030 & 0.020 & 0.046 & 0.020 & -0.055 & 0.732 & -0.029 & 0.056 & -0.143 \\
\hline $\mathrm{AD}$ & 0.061 & -0.020 & 0.596 & -0.001 & 0.040 & -0.038 & 0.081 & -0.005 & 0.167 & 0.041 & -0.042 \\
\hline ON & 0.009 & -0.050 & 0.873 & -0.027 & 0.040 & -0.005 & -0.026 & -0.046 & -0.023 & 0.027 & -0.069 \\
\hline MP & -0.060 & 0.036 & 0.724 & 0.022 & -0.059 & 0.040 & 0.002 & 0.049 & -0.011 & -0.062 & 0.012 \\
\hline $\mathrm{OP}$ & 0.031 & -0.049 & 0.746 & 0.030 & 0.018 & -0.014 & 0.015 & -0.019 & -0.001 & 0.025 & 0.030 \\
\hline PR1 & -0.212 & 0.108 & 0.022 & 0.624 & -0.013 & -0.069 & 0.018 & 0.004 & 0.156 & -0.004 & 0.195 \\
\hline PR2 & -0.067 & 0.124 & 0.111 & 0.772 & -0.048 & -0.024 & 0.022 & 0.058 & -0.066 & -0.008 & 0.006 \\
\hline PR3 & 0.128 & -0.088 & -0.017 & 0.819 & 0.040 & -0.010 & 0.013 & -0.008 & -0.084 & -0.037 & -0.025 \\
\hline PR4 & 0.033 & -0.048 & -0.107 & 0.634 & 0.010 & 0.014 & 0.056 & 0.019 & 0.208 & -0.044 & -0.004 \\
\hline INN1 & -0.058 & -0.054 & 0.062 & 0.127 & 0.008 & 0.047 & -0.080 & -0.044 & 0.674 & 0.039 & 0.023 \\
\hline INN2 & 0.073 & -0.078 & 0.001 & 0.041 & 0.046 & 0.027 & -0.029 & -0.043 & 0.812 & 0.074 & -0.129 \\
\hline INN3 & -0.003 & 0.071 & 0.039 & -0.042 & -0.054 & 0.016 & 0.047 & 0.056 & 0.799 & -0.062 & -0.035 \\
\hline JS1 & -0.045 & 0.080 & 0.052 & -0.040 & -0.019 & 0.024 & -0.003 & -0.007 & 0.068 & 0.806 & 0.140 \\
\hline $\mathrm{JS} 2 \mathrm{r}$ & 0.022 & 0.030 & -0.032 & -0.012 & -0.052 & -0.016 & 0.044 & 0.083 & -0.039 & 0.696 & -0.006 \\
\hline JS3 & 0.006 & -0.006 & -0.006 & -0.035 & 0.022 & -0.044 & 0.008 & -0.012 & 0.004 & 0.821 & -0.016 \\
\hline OV1 & 0.582 & 0.277 & -0.039 & -0.060 & -0.007 & -0.048 & 0.171 & 0.041 & 0.105 & -0.104 & 0.204 \\
\hline OV2 & 0.720 & 0.002 & -0.070 & -0.071 & 0.060 & -0.088 & 0.039 & -0.034 & 0.139 & -0.031 & 0.098 \\
\hline OV3 & 0.823 & -0.077 & 0.080 & -0.018 & -0.016 & 0.022 & -0.017 & 0.075 & -0.035 & -0.025 & 0.029 \\
\hline OV4 & 0.757 & 0.020 & 0.003 & -0.036 & -0.102 & 0.055 & -0.014 & -0.049 & -0.024 & 0.037 & 0.004 \\
\hline OV5 & 0.746 & -0.044 & -0.004 & -0.001 & -0.067 & 0.008 & -0.044 & -0.002 & -0.002 & -0.007 & 0.056 \\
\hline INV1 & 0.271 & 0.110 & 0.090 & -0.089 & 0.058 & -0.110 & -0.035 & 0.098 & 0.052 & -0.023 & 0.530 \\
\hline INV2 & 0.169 & -0.117 & -0.054 & 0.134 & -0.074 & 0.084 & -0.058 & -0.053 & -0.038 & 0.081 & 0.647 \\
\hline INV3 & 0.225 & -0.148 & 0.010 & 0.154 & 0.053 & 0.104 & 0.003 & -0.068 & -0.125 & 0.063 & 0.557 \\
\hline INV4 & -0.208 & 0.016 & -0.050 & -0.075 & 0.057 & -0.013 & 0.000 & -0.008 & -0.059 & 0.005 & 0.825 \\
\hline INS1 & 0.172 & 0.133 & -0.021 & -0.019 & 0.518 & 0.002 & 0.059 & 0.001 & -0.054 & -0.014 & -0.012 \\
\hline INS2 & 0.034 & -0.033 & 0.068 & 0.083 & 0.594 & 0.060 & -0.117 & -0.009 & 0.071 & -0.006 & -0.027 \\
\hline INS3 & 0.044 & 0.152 & 0.011 & -0.002 & 0.672 & 0.034 & 0.008 & -0.022 & -0.030 & 0.020 & -0.056 \\
\hline INS4 & -0.113 & -0.023 & -0.055 & -0.035 & 0.700 & -0.048 & 0.005 & 0.007 & -0.004 & 0.025 & 0.005 \\
\hline INS5 & -0.167 & -0.086 & 0.029 & -0.034 & 0.629 & -0.014 & 0.041 & 0.037 & -0.019 & -0.083 & 0.131 \\
\hline $\mathrm{CO} 1$ & 0.042 & 0.680 & 0.089 & -0.021 & 0.029 & -0.015 & -0.040 & 0.041 & 0.006 & -0.024 & 0.012 \\
\hline $\mathrm{CO} 2$ & -0.036 & 0.860 & -0.006 & 0.044 & -0.051 & -0.015 & 0.014 & -0.056 & -0.061 & 0.032 & -0.035 \\
\hline $\mathrm{CO} 3$ & 0.367 & 0.154 & 0.006 & 0.192 & 0.083 & 0.009 & -0.138 & -0.044 & -0.151 & 0.045 & -0.103 \\
\hline $\mathrm{CO} 4$ & 0.051 & 0.686 & -0.050 & 0.039 & 0.075 & 0.087 & -0.046 & 0.034 & -0.002 & 0.041 & -0.062 \\
\hline $\mathrm{CO} 5$ & -0.062 & 0.829 & -0.120 & 0.011 & 0.014 & 0.031 & 0.004 & -0.046 & 0.020 & 0.052 & -0.053 \\
\hline UN1 & 0.035 & 0.190 & 0.056 & 0.053 & -0.083 & 0.633 & 0.007 & -0.027 & 0.011 & -0.030 & -0.020 \\
\hline UN2 & 0.064 & 0.014 & 0.065 & -0.046 & -0.028 & 0.834 & 0.033 & 0.023 & -0.087 & -0.027 & -0.036 \\
\hline UN3 & 0.027 & -0.087 & -0.100 & -0.013 & 0.091 & 0.711 & 0.000 & -0.007 & 0.090 & 0.024 & 0.013 \\
\hline UN4 & -0.108 & -0.024 & -0.025 & -0.068 & 0.034 & 0.704 & 0.015 & 0.042 & 0.079 & -0.007 & 0.120 \\
\hline ES1 & 0.069 & -0.070 & -0.049 & 0.075 & -0.051 & 0.002 & 0.620 & 0.029 & -0.046 & 0.047 & -0.101 \\
\hline ES2 & -0.036 & 0.041 & -0.010 & 0.009 & -0.053 & -0.001 & 0.759 & -0.015 & 0.037 & -0.035 & 0.022 \\
\hline ES3 & 0.076 & -0.150 & -0.004 & 0.063 & 0.116 & -0.028 & 0.727 & -0.023 & -0.039 & 0.089 & -0.111 \\
\hline ES4 & -0.194 & 0.082 & 0.121 & -0.023 & -0.014 & 0.093 & 0.599 & -0.022 & -0.020 & -0.024 & 0.097 \\
\hline
\end{tabular}

*PR $=\mathrm{ICT}$ productivity, INN=ICT innovation sub-factors of end user performance

$\mathrm{OV}=$ techno overload, INV = techno invasion, $\mathrm{INS}=$ techno insecurity, $\mathrm{CO}=$ techno complexity, $\mathrm{UN}=$ techno uncertainty, sub-factors of technostress creators

$\mathrm{JS}=$ job satisfaction, $\mathrm{ES}=$ end user satisfaction

$\mathrm{AD}=$ alertness to distinction, $\mathrm{ON}=$ openness to novelty, $\mathrm{MP}=$ awareness of multiple perspectives, $\mathrm{OP}=$ orientation in the present, dimensions of IT mindfulness

MAAS $=$ mindfulness sub-factors after conducting parcelling 
Table 2 Convergent validity

\begin{tabular}{lll}
\hline & AVE & CR \\
\hline IT mindfulness & 0.60 & 0.86 \\
Technostress creators & 0.32 & 0.64 \\
End user performance & 0.51 & 0.67 \\
End user satisfaction & 0.50 & 0.79 \\
Job Satisfaction & 0.57 & 0.80 \\
Mindfulness & 0.65 & 0.85 \\
\hline
\end{tabular}

validity was also therefore assessed by calculating the values of Composite Reliability (CR). All CR values exceeded 0.6 thus indicating that convergent validity is established (Hair et al., 2010). On that basis, a decision was made to retain the technostress construct, due to its high conceptual importance and contribution to the theoretical model.

Discriminant validity was assessed by establishing the Fornell Larcker criterion (Fornell \& Larcker, 1981), where AVE values should exceed the corresponding Squared Inter-construct Correlations (SIC) as well as the HTMT criterion where all values fall below the threshold of 0.85 (Hair et al. 2019). Results from our analysis indicate that discriminant validity is established (see Tables 3 and 4).
Nomological validity was tested by ensuring that all covariances between the independent and dependent variables of the CFA model had significant correlations (Hair et al., 2010). In our CFA analysis, all covariances have significant $\mathrm{p}$ values thus nomological validity was established (see Table 5).

\subsubsection{Reliability}

Reliability of the constructs was checked to determine the consistency of their measures using Cronbach's Alpha. All constructs show Cronbach values above 0.8 , validating internal consistency (see Table 6).

\subsubsection{Confirmatory Factory Analysis (CFA) Iterations}

During the CFA process, to ensure the best results in terms of the model fit, reliability, and validity, we deleted items with low factor loadings. As a result, techno-uncertainty was excluded from the second-order construct technostress as it had a very low factor loading $(<0.1)$. Techno overload showed a loading very close to the threshold $(0.5)$ thus its retention in the model was determined (see Table 7). Two iterations of CFA analysis were undertaken, and results are presented on Table 8 . $\mathrm{R}$ square values are presented on Table 9.

Table 3 Fornell Larcker criterion

\begin{tabular}{llllll}
\hline & $\begin{array}{l}\text { Technostress } \\
\text { creators }\end{array}$ & Mindfulness & Job Satisfaction & $\begin{array}{l}\text { End user satis- } \\
\text { faction }\end{array}$ & $\begin{array}{l}\text { IT mindfulness } \\
\text { End user } \\
\text { perfor- } \\
\text { mance }\end{array}$ \\
\hline Technostress creators & 0.536 & & & & \\
Mindfulness & -0.218 & 0.808 & & & 0.701 \\
Job Satisfaction & -0.329 & 0.214 & 0.756 & 0.516 & 0.776 \\
End user satisfaction & -0.435 & 0.171 & 0.407 & 0.668 & 0.748 \\
IT mindfulness & -0.523 & 0.189 & 0.237 & 0.335 & 0.713 \\
End user performance & -0.483 & 0.265 & & \\
\hline
\end{tabular}

Square roots of average variance extracted (AVE) in the diagonal

Table 4 HTMT criterion

\begin{tabular}{llllll}
\hline Technostress & Technostress & Mindfulness & Job satisfaction & $\begin{array}{l}\text { End user satis- } \\
\text { faction }\end{array}$ & $\begin{array}{l}\text { IT mindfulness } \\
\text { End user } \\
\text { perfor- } \\
\text { mance }\end{array}$ \\
\hline Mindfulness & 0.227 & & & \\
Job satisfaction & 0.376 & 0.224 & & \\
End user satisfaction & 0.313 & 0.157 & 0.398 & 0.52 & 0.756 \\
IT mindfulness & 0.29 & 0.197 & 0.231 & 0.676 & \\
End user performance & 0.369 & 0.266 & 0.341 & & \\
\hline
\end{tabular}


Table 5 Covariances matrix

\begin{tabular}{lll}
\hline & Estimate & $\mathrm{P}$ \\
\hline Job satisfaction $<->$ End user satisfaction & 0.111 & $* * *$ \\
Technostress $<->$ mindfulness & -0.024 & .003 \\
End user satisfaction $<->$ technostress & -0.035 & $* * *$ \\
IT mindfulness $<->$ technostress & -0.061 & $* * *$ \\
Technostress $<->$ End user performance & -0.031 & $* * *$ \\
Job satisfaction $<->$ mindfulness & 0.080 & $* * *$ \\
End user satisfaction $<->$ mindfulness & 0.049 & .002 \\
IT mindfulness $<->$ mindfulness & 0.079 & $* * *$ \\
End user performance $<->$ mindfulness & 0.061 & $* * *$ \\
Job satisfaction $<->$ IT mindfulness & 0.094 & $* * *$ \\
Job satisfaction $<->$ End user performance & 0.074 & $* * *$ \\
End user satisfaction $<->$ IT mindfulness & 0.157 & $* * *$ \\
End user satisfaction $<->$ End user performance & 0.113 & $* * *$ \\
IT mindfulness $<->$ End user performance & 0.183 & $* * *$ \\
Job satisfaction $<->$ Technostress & -0.035 & $* * *$ \\
\hline
\end{tabular}

Table 6 Reliability of constructs

\begin{tabular}{lll}
\hline Construct & Items & Cronbach alpha \\
\hline Mindfulness & 15 & 0.843 \\
IT Mindfulness & 4 & 0.855 \\
Job Satisfaction & 3 & 0.796 \\
End user satisfaction & 4 & 0.791 \\
End user performance & 7 & 0.849 \\
Technostress creators & 23 & 0.846 \\
\hline
\end{tabular}

Table 7 CFA loadings for technostress

\begin{tabular}{lc}
\hline Item & Loading \\
\hline Techno complexity - > technostress & 0.659 \\
Techno insecurity- $>$ technostress & 0.622 \\
Techno invasion- $>$ technostress & 0.539 \\
Techno overload- $>$ technostress & 0.442 \\
\hline
\end{tabular}

The model fit indices of the final measurement model are: Chi-square/degrees of freedom $=2.74 ; \mathrm{GFI}=0.91$; AGFI $=0.88 ; \mathrm{NFI}=0.89 ; \mathrm{TLI}=0.91 ; \mathrm{CFI}=0.93$; and RMSEA $=0.059$. The Chi-square/df, values between 1 and 5 suggest a good fit, CFI should be greater than 0.90, RMSEA below 0.08; also, recommended values for GFI $>0.90$ and AGFI $>0.8$ as well as NFI and TLI $>0.90$ suggest a good fit (Salisbury et al., 2002; Schreiber et al., 2006) (see Table 8).

\subsection{Structural Model}

Having achieved an acceptable measurement model, we proceeded to the structural model to test the proposed hypotheses. As shown in Table 10, all values match or pass the cut-offs for each one of the fit indices. The model fit indices of the path model are: Chi-square/degrees of freedom $=3.22 ; \mathrm{GFI}=0.90 ; \mathrm{AGFI}=0.87 ; \mathrm{NFI}=0.87$; $\mathrm{TLI}=0.89 ; \mathrm{CFI}=0.91 ;$ and $\mathrm{RMSEA}=0.067$. The final structural model is presented on Fig. 3.

We also included gender, age, education, and daily IT usage as control variables in our analysis. Results of the analysis showed that the effect of control variables on the dependent variables of the model was not significant, thus they were excluded from the final structural model (see Tables 11 and 12).

Effect sizes have also been calculated for each tested relationship in the model (see Table 13).

\subsubsection{Mediation Analysis}

Mediation analysis confirms technostress as a mediating variable between mindfulness, IT mindfulness and related outcomes (Table 14). In more detail, results show that technostress partially mediates the relationships between mindfulness and job satisfaction $(b=0.055, p<0.05)$, with a direct positive effect $(b=0.122, p<0.05)$ resulting in a total positive effect $(b=0.178, p<0.05)$. Also, technostress partially mediates the relationship between IT mindfulness and user satisfaction $(b=0.139, p<0.001)$ and user performance $(b=0.220, p<0.001)$, with direct positive effect of IT mindfulness on user satisfaction $(b=0.369, p<0.001)$ and user performance $(b=0.524, p<0.001)$ and a total positive effect $(b=0.508, p<0.001)$ and $(b=0.744, p<0.001)$ respectively.

In order to further validate the relationships of the investigated constructs in a nomological network, a post hoc analysis was conducted testing three separate models. Results confirm the validity of our proposed hypotheses as well as establish the protective role of mindfulness and IT mindfulness in a nomological network (see Appendix C).

\subsection{Further Exploratory Analysis: Cluster Analysis}

Cluster analysis was conducted to gain more insights into the investigated sample by better understanding individuals' profiles. More specifically, cluster analysis was used to examine whether employees' tendencies to be mindful and/ or IT mindful are linked with differences in perceptions of technostress as well as levels of satisfaction and performance when using IT for daily work tasks (Crisci et al., 2012; Kolkur \& Kalbande, 2016).

Cluster analysis is concerned with finding structure in unlabelled data points, where the features of the data points within any given cluster share more similarity when compared to other clusters (Lanjewar \& Yadav, 2013; Zadeh et al., 2011) - thus uncovering the relationship between 
Table 8 Fit indices (CFA) measurement model

\begin{tabular}{llll}
\hline Fit index & Recommended value & First CFA & Final CFA \\
\hline$\times 2$ & Non-significant at $\mathrm{p}<0.05$ & 570.04 & 421.87 \\
$\times 2 / \mathrm{df}$ & $5>\times 2 / \mathrm{df}>2$ & 3.28 & 2.74 \\
Goodness of Fit Index (GFI) & $>0.90$ & 0.90 & 0.91 \\
Adjusted Goodness of fit Index (AGFI) & $>0.80$ & 0.86 & 0.88 \\
Root Mean Square Residual (RMR) & the smaller the better, 0 is & 0.04 & 0.03 \\
& considered as perfect fit & & \\
Normed Fit Index (NFI) & $>0.90$ & 0.85 & 0.90 \\
Relative Fit Index (RFI) & $>0.90$ & 0.83 & 0.86 \\
Incremental Index of Fit (IFI) & $>0.90$ & 0.89 & 0.92 \\
Tucker Lewis Index (TLI) & $>0.90$ & 0.87 & 0.91 \\
Comparative Fit Index (CFI) & $>0.90$ & 0.86 & 0.93 \\
Root Mean Square Approximation (RMSEA) & $<0.08$ & 0.06 & 0.06 \\
Parsimony Normed Fit Index (PNFI) & $>0.06$ & 0.71 & 0.72 \\
\hline
\end{tabular}

Table $9 \mathrm{R}^{2}$ values

\begin{tabular}{ll}
\hline Construct & $\mathrm{R}^{2}$ \\
\hline Technostress & 0.362 \\
End user satisfaction & 0.347 \\
End user performance & 0.597 \\
Job satisfaction & 0.195 \\
\hline
\end{tabular}

mindfulness and IT mindfulness. In doing this, we adopted Partitioning Around Medoids (PAM) algorithm as this is more robust to noise, outlier and variable normalization compared to K-means algorithm (Bhat, 2014). The analysis was performed using specialized machine learning packages in R programming language (see Appendix D for more details). Our results provide four clusters of individuals, which constrain the variance in mindfulness and IT mindfulness levels within each cluster - thus we can see some emergence of types - see Table 15. Both variables (mindfulness and IT mindfulness) were selected in order to create the final clusters to uncover any potential interesting insights on the relationships between mindfulness and IT mindfulness and the corresponding scores of technostress, performance, and satisfaction. In presenting some order:
- Cluster 2 represents the most mindful group, characterized by individuals having a high degree of mindfulness and a very high degree of IT mindfulness.

- Cluster 3 represents a group exhibiting a very high degree of mindfulness but medium degree of IT mindfulness.

- Cluster 1 represents a group characterized as individuals with a low degree of mindfulness and high degree of IT mindfulness.

- Cluster 4 represents the least mindful group, showing only average levels of mindfulness and IT mindfulness.

A one-way analysis of variance (ANOVA) was conducted (Hair et al., 2010) showing significant differences among the four clusters in all of the investigated variables; job satisfaction $[F(3,496)=8.150, p<0.001]$, user satisfaction $[\mathrm{F}(3,496)=23.287, \mathrm{p}<0.001]$, performance $[\mathrm{F}(3,496)=45.871, \mathrm{p}<0.001]$, and technostress [F $(3,496)=7.798, p<0.001]$. More details on the clusters are provided on Table 22 in Appendix D.

Examining the clusters in relation to the measures of technostress, performance and satisfaction provides some interesting observations, see Table 15. In this respect Cluster
Table 10 Fit Indices for the structural model

\begin{tabular}{lll}
\hline Fit Index & Recommended Value & $\begin{array}{l}\text { Struc- } \\
\text { tural } \\
\text { model }\end{array}$ \\
\hline$\times 2 / \mathrm{df}$ & $5>\times 2 / \mathrm{df}>2$ & 3.22 \\
Goodness of Fit Index (GFI) & $>0.90$ & 0.90 \\
Adjusted Goodness of fit Index (AGFI) & $>0.80$ & 0.87 \\
Normed Fit Index (NFI) & $>0.90$ & 0.87 \\
Tucker Lewis Index (TLI) & $>0.90$ & 0.88 \\
Comparative Fit Index (CFI) & $>0.90$ & 0.91 \\
Root Mean Square Approximation (RMSEA) & $<0.08$ & 0.06 \\
\hline
\end{tabular}


Fig. 3 Final structural model

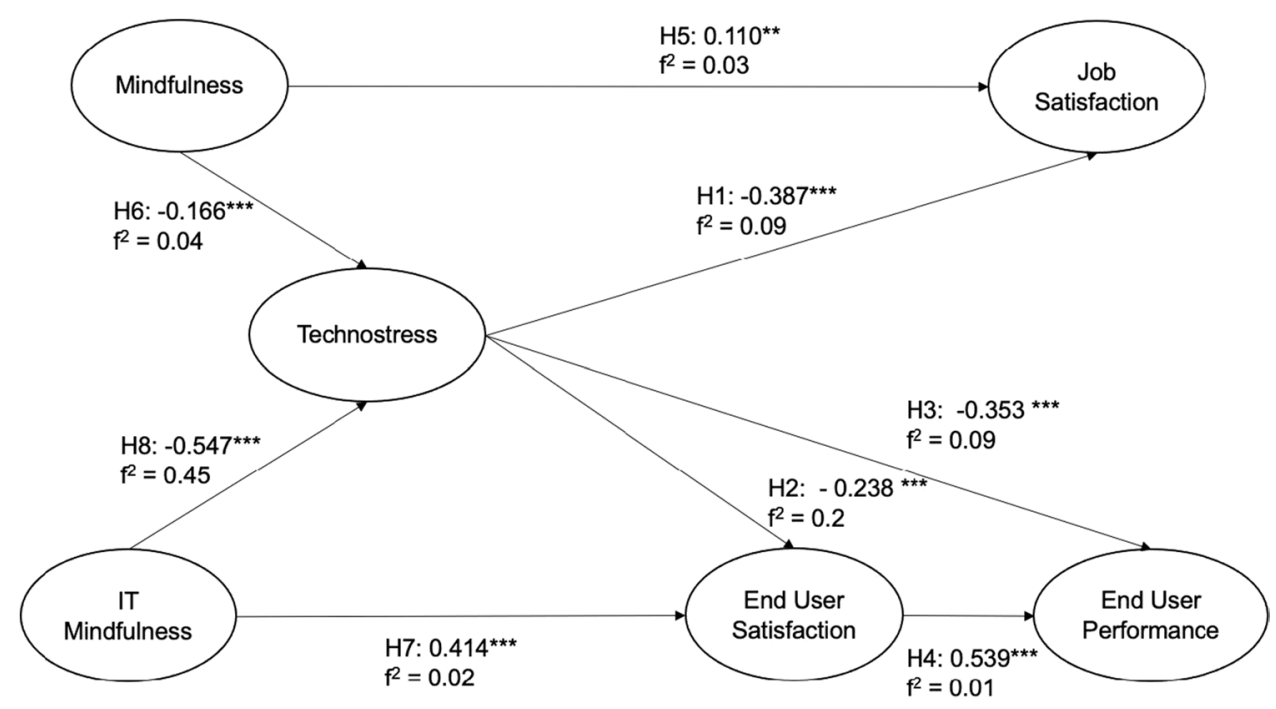

Table 11 Control variables path statistics

\begin{tabular}{lll}
\hline Hypothesis & & Coefficient \\
\hline Gender $->$ & Technostress creators & $0.230 \mathrm{NS}$ \\
Age- $>$ & Technostress creators & $0.008 \mathrm{NS}$ \\
Education $->$ & Technostress creators & $0.001 \mathrm{NS}$ \\
It Usage $->$ & Technostress creators & $-0.032 \mathrm{NS}$ \\
Gender $->$ & End user satisfaction & $-0.056 \mathrm{NS}$ \\
Age $->$ & End user satisfaction & $-0.018 \mathrm{NS}$ \\
Education $->$ & End user satisfaction & $0.036 \mathrm{NS}$ \\
It Usage $->$ & End user satisfaction & $-0.07 \mathrm{NS}$ \\
Gender $->$ & End user performance & $-0.013 \mathrm{NS}$ \\
Education $->$ & End user performance & $-0.005 \mathrm{NS}$ \\
\hline
\end{tabular}

$* * \mathrm{p}<0.001, * \mathrm{p}<0.05$, NS non-significant

2 (the most mindful group), provides the highest scores in relation to end-user performance and end-user satisfaction, alongside the lowest perception of technostress among the four clusters. Conversely, Cluster 4 (the least mindful group), provides the lowest scores in relation to job satisfaction, end-user performance and end-user satisfaction, but has the highest score of technostress. Importantly, Clusters 1 and 3 provide insights on the relationship between mindfulness and IT mindfulness suggesting that IT mindfulness may have a greater predictive power over IT related outcomes than mindfulness. Although participants in both clusters perceived the same (low) level of technostress, there are significant differences in the scores of the IT usage outcomes. Cluster 1 shows higher scores for end-user performance and end-user satisfaction than Cluster 3, revealing that individuals in the first group feel more satisfied and perform better - even though they experience the same levels of technostress as those in Cluster 3. In Cluster 3, however, which is characterized by higher level of mindfulness and medium level of IT mindfulness, a lower level of performance, and user and job satisfaction can be observed.

A hierarchical regression analysis was conducted in order to further assess whether IT mindfulness shows greater predictive power over IT related outcomes, compared to mindfulness, as suggested by the results of clustering analysis. Three steps were followed in the analysis; demographic

Table 12 Tested hypotheses

\begin{tabular}{|c|c|c|}
\hline Hypothesis & Path coefficient & Result \\
\hline H1: Technostress creators are negatively associated with job satisfaction & $-0.387 * * *$ & Supported \\
\hline H2: Technostress creators are negatively associated with end user satisfaction & $-0.238 * * *$ & Supported \\
\hline H3: Technostress creators are negatively associated with end user performance & $-0.353 * * *$ & Supported \\
\hline H4: End user satisfaction is positively associated with end user performance & $0.539 * * *$ & Supported \\
\hline H5: Mindfulness is positively related to job satisfaction & $0.110 * *$ & Supported \\
\hline H6: Mindfulness is negatively associated with technostress creators & $-0.166^{* * *}$ & Supported \\
\hline H7: IT Mindfulness is positively related to end user satisfaction & $0.414 * * *$ & Supported \\
\hline H8: IT Mindfulness is negatively associated technostress creators & $-0.547 * * *$ & Supported \\
\hline
\end{tabular}

$* \mathrm{p}<0.1, * * \mathrm{p}<0.05, * * * \mathrm{p}<0.01, \mathrm{NS} \mathrm{p}>0.1$ 
Table 13 Effect sizes per tested hypothesis

\begin{tabular}{ll}
\hline Hypotheses & $\mathrm{F}^{2}$ \\
\hline H1: Technostress creators - > Job Satisfaction & 0.16 \\
H2: Technostress creators - > User satisfaction & 0.02 \\
H3: Technostress creators - > User performance & 0.09 \\
H4: User satisfaction - > User performance & 0.01 \\
H5: Mindfulness - > Job satisfaction & 0.03 \\
H6: Mindfulness - > Technostress creators & 0.04 \\
H7: IT mindfulness - > User satisfaction & 0.02 \\
H8: IT mindfulness - > Technostress creators & 0.45 \\
\hline
\end{tabular}

variables were entered first as control variables; mindfulness followed in step 2 and IT mindfulness was introduced in step 3.

Results, presented on Table 16, indicate that IT mindfulness shows significant variance in user satisfaction $\left(\mathrm{R}^{2 \text { diff }}=0.141\right)$ beyond mindfulness, as well as on user performance (Adj. $\mathrm{R}^{2 \text { diff }}=0.268$ ) while showing a similar variance in job satisfaction $\left(\mathrm{R}^{2 \text { diff }}=0.019\right)$, with mindfulness $\left(R^{2 \text { diff }}=0.030\right)$. In order to estimate the effect size $\left(\mathrm{f}^{2}\right)$ of IT mindfulness on each of the dependent variables we followed the formula $\mathrm{f}^{2}=\mathrm{R}^{2}$ included $-\mathrm{R}^{2}$ excluded) / (1 - $\mathrm{R}^{2}$ included) (Chin, 1998). Results show that $\mathrm{f}^{2}$ user

Table 14 Mediation analysis

\begin{tabular}{llll}
\hline Hypothesis & Direct effect & Indirect effect & Total effect \\
\hline Mindfulness $->$ technostress- $>$ job satisfaction & $0.122 * *$ & $0.055^{* *}$ & $0.178^{* *}$ \\
IT Mindfulness - > technostress - > user performance & $0.524 * * *$ & $0.220 * * *$ & $0.744 * * *$ \\
IT mindfulness - > technostress - > user satisfaction & $0.369 * * *$ & $0.139 * * *$ & $0.508^{* * *}$ \\
\hline
\end{tabular}

Table 15 Clustering results

\begin{tabular}{|c|c|c|c|c|}
\hline & \multicolumn{2}{|l|}{ Low Mindfulness } & \multicolumn{2}{|l|}{ High Mindfulness } \\
\hline & Low IT Mindfulness & High IT Mindfulness & Low IT Mindfulness & High IT Mindfulness \\
\hline & $\begin{array}{l}\text { Cluster } 4 \\
(\mathrm{~N}=105)\end{array}$ & $\begin{array}{l}\text { Cluster 1 } \\
(\mathrm{N}=165)\end{array}$ & $\begin{array}{l}\text { Cluster } 3 \\
(\mathrm{~N}=99)\end{array}$ & $\begin{array}{l}\text { Cluster } 2 \\
(\mathrm{~N}=131)\end{array}$ \\
\hline Mindfulness & 3.115 & 4.063 & 4.625 & 4.325 \\
\hline IT Mindfulness & 3.456 & 4.037 & 3.436 & 4.718 \\
\hline Technostress & 2.922 & 2.810 & 2.809 & 2.768 \\
\hline Job Satisfaction & 3.140 & 3.289 & 3.205 & 3.226 \\
\hline User Performance & 3.814 & 4.109 & 3.935 & 4.426 \\
\hline User Satisfaction & 3.563 & 3.734 & 3.577 & 3.945 \\
\hline
\end{tabular}

Table 16 Hierarchical regression analysis comparing mindfulness and IT mindfulness power over related outcomes

\begin{tabular}{|c|c|c|c|c|c|c|c|c|c|}
\hline & \multicolumn{3}{|c|}{ user satisfaction } & \multicolumn{3}{|c|}{ user performance } & \multicolumn{3}{|c|}{ job satisfaction } \\
\hline & Step 1 & Step 2 & Step 3 & Step 1 & Step 2 & Step 3 & Step 1 & Step 2 & Step 3 \\
\hline Gender $^{\mathrm{a}}$ & -0.169 & $-0.156^{* * *}$ & $-0.086^{*}$ & $-0.144 * * *$ & $-0.124 * *$ & -0.028 & $-0.104^{*}$ & -0.084 & -0.058 \\
\hline Age & $-0.100 *$ & $-0.112^{* *}$ & -0.070 & -0.054 & -0.072 & -0.013 & 0.016 & -0.001 & 0.015 \\
\hline Education & 0.068 & 0.070 & 0.072 & 0.019 & 0.022 & 0.024 & -0.051 & -0.048 & -0.047 \\
\hline IT usage & 0.077 & 0.070 & -0.021 & $0.148 * * *$ & $0.138 * *$ & 0.012 & 0.062 & 0.052 & 0.019 \\
\hline Mindfulness & & $0.123 * *$ & $0.065 \mathrm{NS}$ & & $0.181 * * *$ & $0.101 * *$ & & $0.175^{* * *}$ & $0.153 * * *$ \\
\hline ITmindfulness & & & $0.403 * * *$ & & & $0.555^{* * *}$ & & & $0.148 * *$ \\
\hline $\mathrm{F}$ & $6.350 * * *$ & $6.703 * * *$ & $21.142 * *$ & $6.411 * * *$ & $8.743 * * *$ & $44.042 * * *$ & 2.279 & $4.957 * * *$ & $5.894 * * *$ \\
\hline Adj. $R^{2}$ & 0.041 & 0.054 & 0.195 & 0.042 & 0.072 & 0.341 & 0.010 & 0.038 & 0.056 \\
\hline $\mathrm{R}^{2}$ difference & & $0.015^{* *}$ & $0.141 * * *$ & & $0.032 * * *$ & $0.268 * * *$ & & $0.030 * * *$ & $0.019 * * *$ \\
\hline
\end{tabular}

$* \mathrm{p}<.05 ; * * \mathrm{p}<.01 ; * * * \mathrm{p}<.001 /{ }^{\mathrm{a} S t a n d a r d i z e d ~ c o e f f i c i e n t s ~ r e p o r t e d ~}$ 
satisfaction $=0.17, \mathrm{f}^{2}$ user performance $=0.41$ and $\mathrm{f}^{2}$ job satisfaction $=0.02$. Following the interpretation of effect sizes, where $\mathrm{f}^{2}$ between 0.02 and 0.15 refers to a small effect size, between 0.15 and 0.35 a medium effect size and greater than 0.35 a large effect size (Cohen, 1988), our results indicate that IT mindfulness shows greater effect for IT related outcomes, user satisfaction (medium effect size with $\mathrm{f}^{2}=0.17$ ) and user performance (large effect size with $\mathrm{f}^{2}=0.41$ ) rather than job related outcomes, and job satisfaction (small effect size $\mathrm{f}^{2}=0.02$ ).

\section{Discussion \& Implications}

\subsection{Key Findings}

Previous studies have argued that current technostress inhibitors (e.g., literacy facilitation, technical support and involvement facilitation) are ineffective in reducing the adverse effects of technostress and more research is needed to identify alternative mechanisms that can combat this phenomenon (Hung et al., 2011). Moreover, empirical evidence on the benefits of incorporating mindfulness in organisational settings has been rather scarce. We have addressed these calls by examining the role of mindfulness and IT mindfulness that can buffer the exposure of technostress and mitigate its negative consequences arising in the workplace. There is a growing body of literature suggesting that mindfulness can decrease general work related stress (Grover et al., 2016; Virgili, 2015; Zimmaro et al., 2016) and improve personal and professional outcomes (Mesmer-Magnus et al., 2017). Our findings showcase the detrimental role of technostress as a mediator (partially) between mindfulness varieties and professional outcomes while also highlight the (overall) beneficial influence of mindfulness and IT mindfulness. Our study, thus, enhances the base of research on this area by demonstrating the role of mindfulness not only in mitigating technostress conditions, but also in enhancing important work-related outcomes (e.g., job satisfaction, end user satisfaction and performance).

In more detail, our results supported all of our proposed hypotheses. At first, we hypothesised that technostress stressors can decrease an individual's job satisfaction (H1). The path was negative and significant $(b=-387$, $\mathrm{p}<0.001)$ thus H1 was confirmed. Second, we hypothesised that people experiencing higher levels of technostress are more likely to have lower satisfaction from IT applications deployed for work tasks (H2). A significant negative correlation was observed $(b=-.238, p=0.007)$ between the constructs, thus $\mathrm{H} 2$ is supported. Third, we hypothesised that technostress negatively affects a user's performance while using IT applications (H3). As expected, a significant negative relationship was found, thus confirming $\mathrm{H} 3$ $(b=-.353, p<0.001)$. Moreover, we hypothesised that an employee's user satisfaction can be positively related with user performance within organisational settings. The path between end-user satisfaction and end-user performance was significant and positive $(b=.539, \mathrm{p}<0.001)$, thus $\mathrm{H} 4$ is supported. Also, we hypothesised that higher levels of individual mindfulness can be positively correlated with the satisfaction an individual perceives from his job. As expected, a significant positive relationship was found between the constructs $(b=.110, p<0.05)$, thus confirming H5. In a similar vein, we hypothesised that IT mindfulness enhances a user's satisfaction with the utilized IT at work. A significant positive relationship between IT mindfulness and end user satisfaction was found $(b=.414$ and $p<0.001)$, thus confirming H7. Last, we hypothesised that mindfulness and IT mindfulness can decrease the impact of technostress stressors (H6) and (H8). A significant negative relationship between mindfulness and technostress creators was obtained $(b=-.166, p<0.01)$ confirming H6 as well as a significant negative path was obtained $(b=-.547$ and $\mathrm{p}<0.001)$ for $\mathrm{H} 8$.

\subsection{Implications for Theory}

Our results both confirm the findings of prior research and provide some novel insights that offer pointers for future research (particularly where that research is of a causal nature).

At first, our findings add to the existing literature demonstrating that IT-induced stress experienced by individuals generates job dissatisfaction and dissatisfaction with IT applications used, and also reduces IT-enabled task performance (H1-H3) (Chen \& Muthitacharoen, 2016; Jena, 2015); while end user satisfaction has a positive impact on end user performance (H4). Our findings suggest that individuals who feel more satisfied with the IT applications they use at work, are more willing to explore further features of the system while also seeking more effective ways to execute their work tasks thus enhancing their performance by becoming more productive as well as innovative (Tarafdar et al., 2010).

Also, our findings suggest a positive relationship between mindfulness and job satisfaction as well as IT mindfulness and user satisfaction (H5 and H7). This indicates that while mindfulness can improve an individual's job satisfaction, IT mindfulness can increase an individual's satisfaction with the technology used for work related tasks (end user satisfaction) thus indirectly improving task performance. Our findings thus, add to the limited base of empirical research supporting the benefits of mindfulness and IT mindfulness in the workplace (Hülsheger et al., 2012; Mesmer-Magnus et al., 2017; Sun et al., 2016).

Furthermore, this study empirically demonstrates that both mindfulness and IT mindfulness can decrease the 
negative consequences of technostress within the workplace (H6 \& H8). Both varieties of mindfulness provide some protection against the negative impact of stressful events that occur while using IT in the workplace (Voci et al., 2016). A more mindful individual is able to adapt and cope more effectively with technostress conditions that arise daily due to the extended use of organisational IT. As a result, a higher degree of mindfulness and IT mindfulness can reduce the unsettling feelings of technostress experienced by individuals as well as mitigate the negative consequences arising from it by enhancing job satisfaction and employee satisfaction with IT and improving task performance.

In terms of novelty, to the best of our knowledge this is one of the first studies empirically demonstrating the dual role of mindfulness and IT mindfulness in: (1) reducing technostress conditions and (2) alleviating its negative consequences at work by enhancing individual outcomes. Past research has argued that organisational mechanisms such as literacy facilitation, technical support and involvement facilitation have been ineffective in counteracting the negative effects of technostress (Hung et al., 2011); while few limited studies have explored the impact of IT mindfulness and technostress on professional outcomes such as job satisfaction. Our study addresses these limitations and expands the IS and management literature by developing and validating a single network for the concepts of mindfulness, IT mindfulness as well as job and IT related outcomes. A wealth of literature has argued that mindfulness may bring significant advantages in the workplace by positively affecting several outcomes such as individual performance, work resilience, engagement, absenteeism, and turnover (Hyland et al., 2015). To date, however, empirical evidence has been scarce (Good et al., 2016). Our study generates valuable insights into the role of mindfulness and IT mindfulness at work, empirically demonstrating their beneficial effects on satisfaction and professional effectiveness at work.

Furthermore, to the best of our knowledge, ours is one of the few empirical studies that consider the concepts of mindfulness and IT mindfulness together. Thatcher et al. (2018), argue for the distinction between mindfulness and IT mindfulness on the basis that, though the concepts share common aspects, they differ in their focus. To this point, however, there is a paucity of research in this area as the state-of-the-art stands and our findings are interesting in this respect. Mindfulness refers to one's propensity to exhibit mindfulness broadly, across various situations and contexts: IT mindfulness is an IT specific trait, describing the behaviour of an individual in specific situations and contexts where an individual is working with technology. As a result, it is logical to propose that an individual could be generally mindful but do not necessarily demonstrate high levels of IT mindfulness. Indeed, this logic plays out in the findings from our analysis (cluster and hierarchical regression) concluding that IT mindfulness should be discriminated from mindfulness, as IT mindfulness holds more predictive power over IT related outcomes in post adoption system use. Overall, our findings offer novel insights on the predictive power of IT mindfulness, compared to mindfulness, providing a solid empirical foundation for future research to further uncover the foundations behind the relationship of the two constructs.

\subsection{Implications for Practice}

Evidence suggests that dispositional mindfulness is a malleable trait and can be enhanced through relevant training programs and interventions (Quaglia et al., 2016). Our results support the beneficial role of mindfulness in the workplace reinforcing a view that companies should embed mindfulness in organisational settings. Indeed, early adopters such as Google, Facebook, Intel, Transport for London (TFL) and recently US Homeland Security (Chaskalson and Hadley, 2015) have been offering in-house tailored sessions to their employees. These can draw on existing mindfulness intervention programs - e.g., Mindfulness-Based Stress Reduction (MBSR) or Mindfulness Based Cognitive Therapy (MBCT) - or be bespoke in nature. Google, for example, has created its own mindfulness program aligned to their organizational goals and values and promoting not only stress reduction but also creativity, autonomy, and joy of work - covering topics such as mindful emailing, mindful listening and dealing with difficult conversations (Glomb et al., 2011). Corporate managers therefore have options available to them.

Our findings here indicate that such programs might be improved and/or more specifically tailored around the concept of IT mindfulness - specifically to counterbalance technostress conditions and their negative consequences. Though IT can offer significant advantages to today's organisations, such as the flexibility to work from home during the covid-19 pandemic, the work-life balance, and the well-being of employees during the time of such crisis can be severely affected by the constant use of technology. Thus, without effective organisational mechanisms that can counterbalance technostress conditions, the appropriation of benefits from technology is dramatically inhibited. Since our findings indicate a difference between mindfulness and IT mindfulness, we suggest that mindfulness training programs can be improved by specifically focusing on mindful 
ways of dealing with techno stressors (e.g., techno invasion, techno overload, techno insecurity, techno uncertainty and techno complexity). Our results indicate that this focus has the potential to further improve end-user performance and end-user satisfaction and the consequences that would flow from that.

\subsection{Limitations and Future Work}

In terms of limitations, alternative methods for measuring technostress, mindfulness, IT mindfulness and task performance could be used in future research in order to address the limitations of self-reported measures. Also, although previous research has established the validity of the adopted short version instrument for IT mindfulness, it is important for future research to replicate our results using the full instrument in order to explore any potential differences in the derived outcomes. Regarding the use of the already established technostress instrument, one technostressor (i.e., techno-uncertainty) had to be dropped from the main data analysis; revealing the potential need for a revision of the instrument in order to ensure content validity that might derive from the rapid emergence of new technologies at work (Fischer \& Riedl, 2019). Moreover, the current study deployed convenience sampling, a wellestablished technique in the social sciences; however, future research should replicate our results using other sampling techniques in order to enhance the generalisability of findings. Also, future research should be conducted using a longitudinal approach measuring actual behaviours rather than perceptions, such as deploying mindfulness intervention programs that could yield causal inferences for the influence of mindfulness on technostress. In addition, future studies should consider using diverse populations, and sectors that could reveal different results. Future research should concentrate on different organisational outcomes such as organisational commitment and turnover intention characterizing people included in the clusters. Such investigations would increase our knowledge in the effects of mindfulness on technostress and a variety of individual outcomes within the workplace. At last, the present study examined the impact of mindfulness as a personality trait on technostress and work-related outcomes; it would be interesting for future research to explore the influence of other personality characteristics (e.g., big five personality traits) along with mindfulness in order to examine potential confounding effects.

\section{Conclusion}

Using structural equation modelling to test the proposed theoretical model and cluster analysis to identify the different groups among the participants based on their mindfulness and IT mindfulness levels, our study contributes to IS research, offering insights on the role of mindfulness and IT mindfulness in decreasing technostress and improving professional outcomes within the workplace. Our findings reveal that more mindful, and IT mindful employees are able to deal more effectively with technostress conditions that arise within the workplace experiencing less technostress feelings as well as greater job and user satisfaction and enhanced task performance compared to less mindful employees. Moreover, our findings reveal that IT mindfulness has more influence on task performance than mindfulness per se, providing more insights into the relationship between mindfulness and IT mindfulness that has been neglected by previous studies.

IT offers significant benefits both to individuals and organisations, such as during the Covid-19 pandemic where technology played a primary role in aiding remote working environments; however, the use of technology can also cause negative consequences on employees' well-being and professional outcomes. Technostress is a key management concern as it can severely affect employees' well-being and work life in ways that can significantly influence organisational efficiency and overall success. The present study contributes and expands IS literature by identifying mindfulness and IT mindfulness as prevention mechanisms that can be used within organisational settings in order to combat IT induced stress and mitigate its negative consequences. The results of our analysis offer practical value in developing, planning, and implementing targeted interventions within organisational settings. Thus, by implementing mindfulness and IT mindfulness as interventions to enhance individual mindfulness of employees, organisations have a powerful tool that can protect employees from the negative consequences of technostress, enhance wellbeing at work and increase individual outcomes thus improving the overall performance of the organisation. 


\section{Appendix A}

Table 17 Demographics

\begin{tabular}{|c|c|c|c|}
\hline Measures & Items & Frequency & Percentage \\
\hline \multirow[t]{2}{*}{ Gender } & Male & 262 & 52.4 \\
\hline & Female & 238 & 47.6 \\
\hline \multirow[t]{6}{*}{ Age } & $<26$ & 53 & 10.6 \\
\hline & $26-35$ & 246 & 49.2 \\
\hline & $36-45$ & 112 & 22.4 \\
\hline & $46-55$ & 59 & 11.8 \\
\hline & $56-65$ & 26 & 5.2 \\
\hline & $>65$ & 4 & 8.0 \\
\hline \multirow[t]{6}{*}{ Education } & High School & 11 & 2.2 \\
\hline & 2-year college & 25 & 5.0 \\
\hline & Bachelor & 202 & 40.4 \\
\hline & Master & 198 & 39.6 \\
\hline & $\mathrm{PhD}$ & 55 & 11.0 \\
\hline & Other & 9 & 1.8 \\
\hline \multirow[t]{4}{*}{ Total work experience } & $1-5$ years & 128 & 25.6 \\
\hline & $6-10$ years & 157 & 31.4 \\
\hline & $11-15$ years & 94 & 18.8 \\
\hline & Over 16 years & 121 & 24.2 \\
\hline \multirow[t]{4}{*}{ Current work experience } & $1-5$ years & 286 & 57.2 \\
\hline & $6-10$ years & 137 & 27.4 \\
\hline & $11-15$ years & 51 & 10.2 \\
\hline & Over 16 years & 26 & 5.2 \\
\hline \multirow[t]{3}{*}{ Daily IT usage } & $<3 \mathrm{~h}$ & 15 & 3.0 \\
\hline & $3-6 \mathrm{~h}$ & 73 & 14.6 \\
\hline & $>6 \mathrm{~h}$ & 412 & 84.4 \\
\hline
\end{tabular}


Table 18 Survey instrument

\begin{tabular}{lrl}
\hline Measures & Mean & SD \\
\hline End user performance & & \\
PR1 This technology helps to improve the quality of my work. & 4.17 & 0.60 \\
PR2 This technology helps to improve my productivity. & 4.27 & 0.72 \\
PR3 This technology helps me to accomplish more work than would otherwise be pos- & 4.54 & 0.68 \\
sible & & \\
PR4 This technology helps me to perform my job better. & 4.28 & 0.68 \\
INN1 This technology helps me to identify innovative ways of doing my job. & 3.87 & 0.83 \\
INN 2This technology helps me to come up with new ideas relating to my job. & 3.86 & 0.84 \\
INN3 This technology helps me to try out innovative ideas. & 3.71 & 0.85
\end{tabular}

Technostress creators

Techno-overload

I1_1_I am forced by this technology to work much faster.

$3.00 \quad 0.98$

I1_2 - I am forced by this technology to do more work than I can handle. $\quad 2.90 \quad 0.87$

I1_3 - I am forced by this technology to work with very tight time schedules. $\quad 3.64 \quad 1.10$

I1_4-I am forced to change my work habits to adapt to new technologies. $\quad 3.53 \quad 0.94$

I1_5-I have a higher workload because of increased technology complexity. $\quad 3.40 \quad 1.00$

Techno-invasion

I1_8-I spend less time with my family due to this technology. $\quad 2.59 \quad 1.02$

I1_9—I have to be in touch with my work even during my vacation due to this technol- $3.15 \quad 1.04$ ogy.

I1_10_I have to sacrifice my vacation and weekend time to keep current on new $\quad 2.60 \quad 0.96$ technologies.

I1_11-I feel my personal life is being invaded by this technology. $\quad 2.28 \quad 1.15$

Techno-complexity

I1_12 - I do not know enough about this technology to handle my job satisfactorily. $\quad 2.06 \quad 0.98$

I1_13 — I need a long time to understand and use new technologies. $\quad 1.96 \quad 0.96$

I1_14-I do not find enough time to study and upgrade my technology skills. $\quad 3.34 \quad 1.02$

I1_15_I find new recruits to this organisation know more about computer technology $\quad 2.67 \quad 0.93$ than I do.

I1_16-I often find it too complex for me to understand and use new technologies. $\quad 1.97 \quad 0.94$

Techno-insecurity

I1_17-I feel constant threat to my job security due to new technologies. $\quad 2.36 \quad 0.86$

I1_18_I have to constantly update my skills to avoid being replaced. $\quad 3.16 \quad 0.92$

I1_19-I am threatened by co-workers with newer technology skills. $\quad 2.52 \quad 0.94$

I1_20-I do not share my knowledge with my co-workers for fear of being replaced. $\begin{array}{lll}1.95 & 0.83\end{array}$

I1_21-I feel there is less sharing of knowledge among co-workers for fear of being $\quad \begin{array}{rr}2.53 & 0.99\end{array}$ replaced.

Techno-uncertainty

I1_22_-There are always new developments in the technologies we use in our organisa- $3.51 \quad 0.79$ tion.

I1_23-There are constant changes in computer software in our organisation.

$3.42 \quad 0.82$

I1_24-There are constant changes in computer hardware in our organisation. $\quad \begin{array}{lll}2.92 & 0.87\end{array}$

I1_25-There are frequent upgrades in computer networks in our organisation. $\quad 3.13 \quad 0.85$

Job satisfaction

(Cammann et al., 1979)

JS1 All in all, I am satisfied with my job. $\quad 3.73 \quad 0.77$

JS2 In general, I don't like my job. $\quad 3.90 \quad 0.85$

JS3 In general, I like working here. $\quad 3.97 \quad 0.90$

End user Satisfaction

ES1 I am with my use of I CT's in connection with my work tasks.

ES2 I am with my use of ICT's in connection with my work tasks.

ES3 I am with my use of ICT's in connection with my work tasks.
Tarafdar et al., 2010)

(Tarafdar et al., 2010)

Tarafdar et al., 2010)

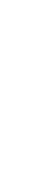

(1)


Table 18 (continued)

\begin{tabular}{|c|c|c|c|}
\hline Measures & Mean & SD & Reference \\
\hline $\begin{array}{l}\text { ES4 I am _ with my use of ICT's in connection with my work tasks. } \\
\text { IT Mindfulness }\end{array}$ & 3.44 & 0.59 & $\begin{array}{l}\text { Absolutely Terrible/Absolutely Delighted } \\
\text { (Thatcher et al., 2018) }\end{array}$ \\
\hline AD I am very creative when using this technology. & 3.59 & 0.88 & \\
\hline ON I am often open to learning new ways of using this technology. & 4.09 & 0.89 & \\
\hline MP I like to figure out different ways of using this technology. & 4.21 & 0.77 & \\
\hline OP I get involved when 'using' this technology. & 4.00 & 0.83 & \\
\hline Mindfulness & & & (Brown \& Ryan, 2003) \\
\hline I could be experiencing some emotion and not be conscious of it until sometime later. & 4.60 & 1.12 & \\
\hline $\begin{array}{l}\text { I break or spill things because of carelessness, not paying attention, or thinking of } \\
\text { something else. }\end{array}$ & 4.69 & 0.98 & \\
\hline I find it difficult to stay focused on what's happening in the present. & 4.02 & 1.13 & \\
\hline $\begin{array}{l}\text { I tend to walk quickly to get where I'm going without paying attention to what I experi- } \\
\text { ence along the way. }\end{array}$ & 3.72 & 1.25 & \\
\hline $\begin{array}{l}\text { I tend not to notice feelings of physical tension or discomfort until they really grab my } \\
\text { attention. }\end{array}$ & 4.14 & 1.18 & \\
\hline I forget a person's name almost as soon as I've been told it for the first time. & 3.14 & 1.25 & \\
\hline It seems I am "running on automatic," without much awareness of what I'm doing. & 4.01 & 1.16 & \\
\hline I rush through activities without being really attentive to them. & 4.12 & 1.12 & \\
\hline $\begin{array}{l}\text { I get so focused on the goal I want to achieve that I lose touch with what I'm doing } \\
\text { right now to get there. }\end{array}$ & 4.26 & 1.22 & \\
\hline I do jobs or tasks automatically, without being aware of what I'm doing. & 4.20 & 1.13 & \\
\hline I find myself listening to someone with one ear, doing something else at the same time. & 3.18 & 1.17 & \\
\hline I drive places on 'automatic pilot' and then wonder why I went there. & 4.56 & 1.21 & \\
\hline I find myself preoccupied with the future or the past. & 3.18 & 1.18 & \\
\hline I snack without being aware that I'm eating. & 4.04 & 1.17 & \\
\hline I find myself doing things without paying attention. & 4.86 & 1.21 & \\
\hline
\end{tabular}

\section{Appendix B}

\section{Sample Size Estimation using $G$ power analysis}

Our results show that for an observed effect size $d=0.03$ a $\mathrm{N}$ of approximately 161 would be needed to obtain statistical power at the recommended 0.80 level with 0.05 probability level; while for an observed effect size $d=0.05$ a $\mathrm{N}$ of approximately 156 would be needed to obtain statistical power at the recommended 0.80 level with 0.05 probability level (Cohen, 1988).

\section{Confirmatory Factory Analysis (CFA)}

\subsection{Item Parcelling}

Mindfulness was modelled as a second order construct following previous mindfulness research. The majority of previous studies that have employed the Mindfulness (MAAS) instrument, consisting of 15 items, have created item parcels in order to reduce the number of the items as well as the complexity of the model and also increase the standardized weights of the mindfulness items (Little et al., 2002; Coffey and Hartman, 2008; Kiken \& Shook, 2012; Pearson et al., 2015). Following previous studies (Little et al., 2002; Pearson et al., 2015), the researcher first conducted Exploratory Factor Analysis (EFA) using
Maximum Likelihood and extraction of the only factor and then created three parcels by combining the items with the highest loadings with the items with the lowest ones. The first parcel (MAAS1) items were M7, M2, M10, M15 and M8, while the second parcel (MAAS2) included M14, M6, M4, M3 and M12 and the third parcel (MAAS3) included

Table 19 Item parcelling for mindfulness

\begin{tabular}{ll}
\hline Item & Loading \\
\hline M1 & 0.45 \\
M2 & 0.31 \\
M3 & 0.42 \\
M4 & 0.53 \\
M5 & 0.49 \\
M6 & 0.38 \\
M7 & 0.75 \\
M8 & 0.72 \\
M9 & 0.42 \\
M10 & 0.74 \\
M11 & 0.45 \\
M12 & 0.53 \\
M13 & 0.44 \\
M14 & 0.72 \\
M15 & 0.32
\end{tabular}


items M5, M11, M9, M13 and M1. Table 19 presents the loading of each indicator before the development of the parcels.

\subsection{Higher Order Constructs}

All variables included in the proposed model, technostress, mindfulness, IT mindfulness end user satisfaction and performance, job satisfaction were conceived as reflective constructs following their original conceptualisation studies (Bhattacherjee, 2001; Brown \& Ryan, 2003; Cammann et al., 1979; Ragu-Nathan et al., 2008; Tarafdar et al., 2010; Thatcher et al., 2018). We validated the existence of the second order constructs for technostress creators and end-user performance by calculating the target coefficient (the ratios of the chi squares of the first order model and the second order model). Both $\mathrm{t}$-coefficients were above the recommended value of 0.8 (Marsh \& Hocevar, 1985), thus confirming our secondorder models.

\section{Appendix C}

\section{Post Hoc Analysis - Testing Mindfulness and IT mindful- ness in a nomological network}

Having established the proposed theoretical model, we proceeded in a post hoc analysis testing three different models assessing the relationships between the constructs: (1) one model including only mindfulness, (2) one model including only IT mindfulness and (3) one model including both mindfulness and IT mindfulness. This post hoc analysis aimed at establishing the strength of the nomological network on the impact of mindfulness and IT mindfulness on the dependent variables. Also, in all three models we tested for additional relationships that didn't exist in our original model aiming to explore such potential associations (H9-H10).

Evidence suggests that job satisfaction has a positive impact on work performance (Aftab, 2012; Tahir Iqbal et al., 2012) thus it is expected that job satisfaction will have a positive influence on user performance (H9). According to previous studies (Ang \& Koh, 1997; Ang \& Soh, 1997), user satisfaction is an indication of job satisfaction thus we hypothesized that user satisfaction will have a positive impact on job satisfaction (H10). Results of the post hoc analysis show that all hypotheses from the original proposed model (H1 - H8) are confirmed in all three models thus establishing the strength of the nomological network. Furthermore, results show that user satisfaction has a positive association with job satisfaction (H10) while an insignificant effect of job satisfaction on user performance (H9) was found. For all three models fit indices exceed the recommended thresholds (see Table 20), suggesting a good fit.
Table 20 Fit indices per model

\begin{tabular}{llll}
\hline & Model 1 & Model 2 & Model 3 \\
\hline Cmin & 341.097 & 366.805 & 492.731 \\
Cmin/df & 3.553 & 3.335 & 3.119 \\
RMR & 0.034 & 0.039 & 0.037 \\
GFI & 0.918 & 0.917 & 0.904 \\
AGFI & 0.884 & 0.884 & 0.873 \\
CFI & 0.905 & 0.915 & 0.911 \\
RMSEA & 0.072 & 0.068 & 0.065 \\
NFI & 0.874 & 0.884 & 0.875 \\
TLI & 0.881 & 0.895 & 0.893 \\
\hline
\end{tabular}

Comparing the path coefficients of the tested hypotheses across the three models, some observations can be noted: when IT mindfulness is absent (Model 1), technostress shows a much stronger impact on user satisfaction than in the rest of the models (almost $44 \%$ difference), signifying the protection role of IT mindfulness in mitigating the negative effects of technostress on user satisfaction. Also, the association between mindfulness and technostress is stronger in Model 2, while the impact of IT mindfulness on technostress is the strongest $(b=-0.555)$ in Model 2, signifying the important protective role that mindfulness and IT mindfulness offer in tackling technostress (Table 21).

\section{Appendix D}

\section{Cluster Analysis}

As it is the standard practice, a feature selection method using the Boruta package in R (Kursa \& Rudnicki, 2010) was applied to confirm that the variables related to mindfulness and IT mindfulness are all important and suitable for cluster analysis. Then, the optimal number of clusters was determined as four using the elbow method, which represents the total Within-cluster Sum of Square (WSS) curve for the features (variables) used in the cluster analysis - see Fig. 4 (Kodinariya \& Makwana, 2013; Othata \& Pantaragphong, 2017). The resulting cluster plot is illustrated in Fig. 5.

PAM algorithm performs clustering using K-Medoids to represent the cluster ( $\mathrm{Li}$ et al., 2017), where a medoid is defined as the centre point within the cluster whose average dissimilarity to all other data points in the cluster is minimal (i.e., it is the most centrally-located point in the cluster). In operation, the PAM algorithm randomly assigns initial medoids to represent the $\mathrm{K}$ clusters, then, runs through iterations of assigning the rest of the data points to the $\mathrm{K}$ clusters, selecting new data points as medoids, and re-assigning the data points to the new 
Table 21 Path coefficients per model

\begin{tabular}{llll}
\hline Hypotheses & Model 1 & Model 2 & Model 3 \\
\hline H1: Technostress creators- > Job Satisfaction & $-0.266^{* * *}$ & $-0.205^{* *}$ & $-0.193^{* *}$ \\
H2: Technostress creators - > User satisfaction & $-0.341^{* * *}$ & $-0.184^{* *}$ & $-0.188^{* *}$ \\
H3: Technostress creators - > User performance & $-0.202^{* *}$ & $-0.292^{* * *}$ & $-0.314^{* * *}$ \\
H4: User satisfaction - > User performance & $0.591^{* * *}$ & $0.581^{* * *}$ & $0.568^{* * *}$ \\
H5: Mindfulness - > Job satisfaction & $0.096^{*}$ & - & $0.113^{* *}$ \\
H6: Mindfulness - > Technostress creators & $-0.261^{* * *}$ & - & $-0.153^{* *}$ \\
H7: IT mindfulness - > User satisfaction & - & $0.451^{* * *}$ & $0.446^{* * *}$ \\
H8: IT mindfulness - > Technostress creators & - & $-0.555^{* * *}$ & $-0.531^{* * *}$ \\
H9: Job satisfaction - > User performance & $0.034 \mathrm{NS}$ & $0.012 \mathrm{NS}$ & $0.010 \mathrm{NS}$ \\
H10: User satisfaction - > Job satisfaction & $0.298^{* * *}$ & $0.313^{* * *}$ & $0.297^{* * *}$ \\
\hline
\end{tabular}

$* * * \mathrm{p}<0.001, * * \mathrm{p}<0.05, * \mathrm{p}<0.1, \mathrm{NS}$ medoids until it reaches medoids with stabilized locations. Ultimately, the PAM algorithm aims to minimize the absolute distance between the data points and the medoids. PAM method requires the number of clusters (K) to be determined before running the clustering algorithms. Thus, in order to determine the optimal number of clusters K, the elbow method can be used (Othata \& Pantaragphong, 2017; Kodinariya \& Makwana, 2013). The idea here is to run the cluster analysis several times (starting from $K=2$ to $K=15$ ), and to calculate the cost of training the model, namely total Within-cluster Sum of Square (WSS). Then, by plotting the curve for WSS values against the number of clusters $(\mathrm{K})$ as displayed in the sample curve in Fig. 4, it can be noticed that the WSS curve goes down rapidly until reaching an elbow point where $K=4$, and then it starts to change very slowly. The bend point represents the approximate optimal number of clusters.

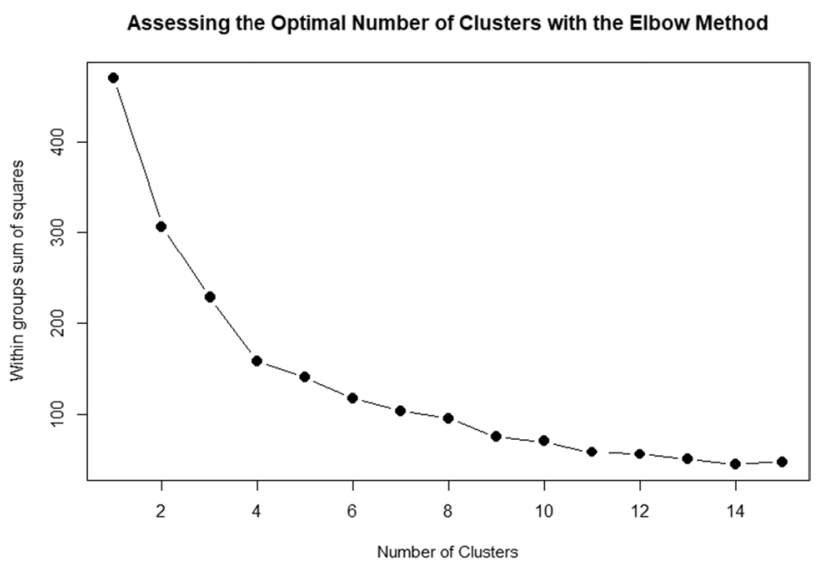

Fig. 4 WSS curve - optimal number of clusters
Figure 5 depicts the 4 resulting clusters. The characteristics of these clusters are as follows:

- Cluster 1 (red) represents a group characterized as individuals with a low degree of mindfulness and high degree IT mindfulness.

- Cluster 2 (green) represents the most mindful group, characterized by individuals having a high degree of mindfulness and a very high degree of IT mindfulness.

- Cluster 3 (turquoise) represents a group exhibiting a very high degree of mindfulness but medium degree of IT mindfulness.

- Cluster 4 (purple) represents the least mindful group, showing only average levels of mindfulness and IT mindfulness.

Table 22 lists summary of the statistics resulting from the cluster analysis.

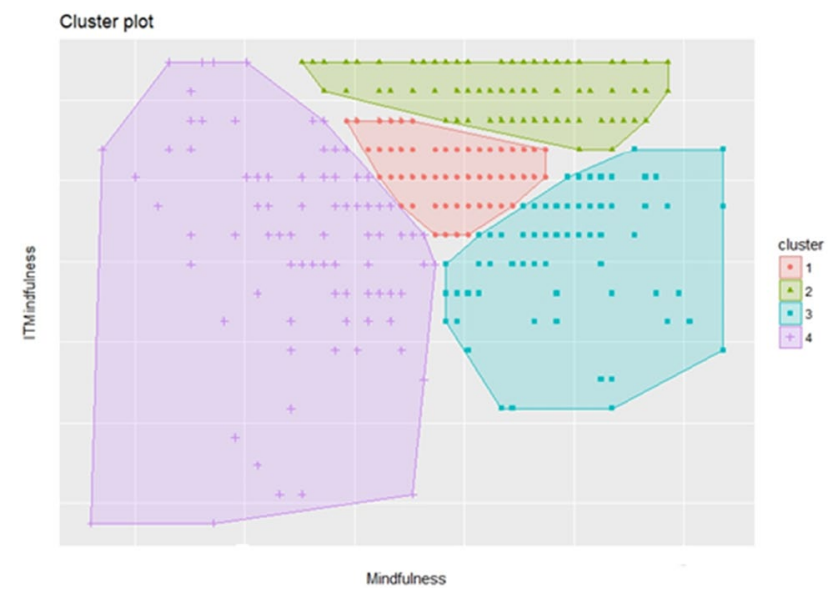

Fig. 5 Clusters plot 
Table 22 Summary of clusters statistics

\begin{tabular}{|c|c|c|c|c|c|c|c|c|c|c|}
\hline Cluster & Variable & $\mathrm{n}$ & Mean & St.d & median & $\min$ & $\max$ & skew & kurtosis & se \\
\hline 1 & Mindfulness & 165 & 4.06 & 0.31 & 4.07 & 3.33 & 4.53 & -0.35 & -1.01 & 0.02 \\
\hline 1 & IT Mindfulness & 165 & 4.04 & 0.24 & 4.00 & 3.50 & 4.50 & -0.19 & -0.33 & 0.02 \\
\hline 1 & End Use Performance & 165 & 4.11 & 0.39 & 4.14 & 2.57 & 5.00 & -0.37 & 0.54 & 0.03 \\
\hline 1 & Job Satisfaction & 165 & 3.29 & 0.33 & 3.33 & 2.00 & 4.00 & -0.75 & 1.00 & 0.03 \\
\hline 1 & End User Satisfaction & 165 & 3.73 & 0.36 & 3.75 & 2.75 & 4.75 & -0.42 & 0.48 & 0.03 \\
\hline 1 & Technostress & 165 & 2.81 & 0.36 & 2.76 & 1.50 & 3.83 & 0.10 & 0.95 & 0.03 \\
\hline 1 & Gender & 165 & 1.40 & 0.49 & 1.00 & 1.00 & 2.00 & 0.40 & -1.85 & 0.04 \\
\hline 1 & Age & 165 & 2.37 & 0.83 & 2.00 & 1.00 & 5.00 & 1.37 & 2.05 & 0.06 \\
\hline 1 & Education & 165 & 3.53 & 0.77 & 3.00 & 1.00 & 6.00 & 0.15 & 1.24 & 0.06 \\
\hline 1 & Total work experience & 165 & 2.24 & 0.95 & 2.00 & 1.00 & 4.00 & 0.43 & -0.72 & 0.07 \\
\hline 1 & Current work experience & 165 & 1.57 & 0.71 & 1.00 & 1.00 & 4.00 & 1.03 & 0.46 & 0.05 \\
\hline 1 & IT usage & 165 & 2.86 & 0.43 & 3.00 & 1.00 & 3.00 & -3.06 & 8.84 & 0.03 \\
\hline 2 & Mindfulness & 131 & 4.33 & 0.48 & 4.33 & 3.07 & 5.27 & -0.45 & -0.01 & 0.04 \\
\hline 2 & IT Mindfulness & 131 & 4.72 & 0.21 & 4.75 & 4.25 & 5.00 & -0.01 & -1.04 & 0.02 \\
\hline 2 & End Use Performance & 131 & 4.43 & 0.43 & 4.43 & 3.29 & 5.00 & -0.21 & -0.77 & 0.04 \\
\hline 2 & Job Satisfaction & 131 & 3.23 & 0.41 & 3.33 & 2.00 & 4.67 & -0.37 & 1.19 & 0.04 \\
\hline 2 & End User Satisfaction & 131 & 3.95 & 0.56 & 4.00 & 1.25 & 5.00 & -0.58 & 3.03 & 0.05 \\
\hline 2 & Technostress & 131 & 2.77 & 0.46 & 2.77 & 1.35 & 3.82 & -0.62 & 1.21 & 0.04 \\
\hline 2 & Gender & 131 & 1.40 & 0.49 & 1.00 & 1.00 & 2.00 & 0.41 & -1.85 & 0.04 \\
\hline 2 & Age & 131 & 2.56 & 0.99 & 2.00 & 1.00 & 6.00 & 0.87 & 0.64 & 0.09 \\
\hline 2 & Education & 131 & 3.63 & 0.87 & 4.00 & 1.00 & 6.00 & 0.36 & 0.31 & 0.08 \\
\hline 2 & Total work experience & 131 & 2.47 & 1.09 & 2.00 & 1.00 & 4.00 & 0.10 & -1.31 & 0.09 \\
\hline 2 & Current work experience & 131 & 1.58 & 0.89 & 1.00 & 1.00 & 4.00 & 1.49 & 1.28 & 0.08 \\
\hline 2 & IT usage & 131 & 2.95 & 0.22 & 3.00 & 2.00 & 3.00 & -3.96 & 13.80 & 0.02 \\
\hline 3 & Mindfulness & 99 & 4.63 & 0.38 & 4.60 & 3.93 & 5.60 & 0.39 & -0.15 & 0.04 \\
\hline 3 & IT Mindfulness & 99 & 3.44 & 0.48 & 3.50 & 2.00 & 4.25 & -1.11 & 1.07 & 0.05 \\
\hline 3 & End User Performance & 99 & 3.93 & 0.46 & 4.00 & 2.86 & 5.00 & 0.10 & 0.13 & 0.05 \\
\hline 3 & Job Satisfaction & 99 & 3.20 & 0.43 & 3.33 & 1.33 & 5.00 & -0.57 & 5.36 & 0.04 \\
\hline 3 & End User Satisfaction & 99 & 3.58 & 0.50 & 3.50 & 2.25 & 5.00 & 0.29 & 0.18 & 0.05 \\
\hline 3 & Technostress & 99 & 2.81 & 0.42 & 2.83 & 1.72 & 3.86 & 0.10 & -0.56 & 0.04 \\
\hline 3 & Gender & 99 & 1.53 & 0.50 & 2.00 & 1.00 & 2.00 & -0.14 & -2.00 & 0.05 \\
\hline 3 & Age & 99 & 2.76 & 1.33 & 3.00 & 1.00 & 6.00 & 0.49 & -0.58 & 0.13 \\
\hline 3 & Education & 99 & 3.46 & 0.99 & 3.00 & 1.00 & 6.00 & -0.25 & 0.16 & 0.10 \\
\hline 3 & Total work experience & 99 & 2.65 & 1.23 & 3.00 & 1.00 & 4.00 & -0.19 & -1.58 & 0.12 \\
\hline 3 & Current work experience & 99 & 1.77 & 0.96 & 1.00 & 1.00 & 4.00 & 1.00 & -0.12 & 0.10 \\
\hline 3 & IT usage & 99 & 2.62 & 0.56 & 3.00 & 1.00 & 3.00 & -1.16 & 0.32 & 0.06 \\
\hline 4 & Mindfulness & 105 & 3.12 & 0.46 & 3.20 & 1.80 & 3.87 & -0.60 & -0.20 & 0.04 \\
\hline 4 & IT Mindfulness & 105 & 3.46 & 0.86 & 3.50 & 1.00 & 5.00 & -0.80 & 0.86 & 0.08 \\
\hline 4 & End User Performance & 105 & 3.81 & 0.70 & 3.86 & 1.00 & 5.00 & -0.97 & 3.11 & 0.07 \\
\hline 4 & Job Satisfaction & 105 & 3.14 & 0.40 & 3.33 & 1.67 & 4.00 & -1.07 & 2.29 & 0.04 \\
\hline 4 & End User Satisfaction & 105 & 3.56 & 0.62 & 3.50 & 1.50 & 5.00 & -0.46 & 0.92 & 0.06 \\
\hline 4 & Technostress & 105 & 2.92 & 0.57 & 2.97 & 1.24 & 4.53 & -0.07 & 0.21 & 0.06 \\
\hline 4 & Gender & 105 & 1.62 & 0.49 & 2.00 & 1.00 & 2.00 & -0.47 & -1.79 & 0.05 \\
\hline 4 & Age & 105 & 2.58 & 1.16 & 2.00 & 1.00 & 6.00 & 0.64 & -0.16 & 0.11 \\
\hline 4 & Education & 105 & 3.71 & 1.02 & 4.00 & 1.00 & 6.00 & -0.41 & 0.51 & 0.10 \\
\hline 4 & Total work experience & 105 & 2.37 & 1.24 & 2.00 & 1.00 & 4.00 & 0.21 & -1.59 & 0.12 \\
\hline 4 & Current work experience & 105 & 1.67 & 0.98 & 1.00 & 1.00 & 4.00 & 1.16 & 0.00 & 0.09 \\
\hline 4 & IT usage & 105 & 2.64 & 0.60 & 3.00 & 1.00 & 3.00 & -1.46 & 1.01 & 0.06 \\
\hline
\end{tabular}




\section{Declarations}

Conflict of Interest The authors have no relevant financial or non-financial interests to disclose.

\section{References}

Aanestad, M., \& Jensen, T. B. (2016). Collective mindfulness in post-implementation IS adaptation processes. Information and Organization, 26(1-2), 13-27. https://doi.org/10.1016/j.infoa ndorg.2016.02.001

Aftab, H. (2012). A study of job satisfaction and IT's impact on the performance in the banking industry of Pakistan. In International journal of business and social science (Vol. 3, Issue 19). www. ijbssnet.com

Agogo, D., \& Hess, T. J. (2015). Technostress and technology induced state anxiety: Scale development and implications. In Thirty sixth international conference on information systems, Fort Worth 2015 (pp. 1-11).

Alberts, H. J. E. M., \& Hülsheger, U. R. (2015). Applying mindfulness in the context of work: Mindfulness based interventions. In J. Reb \& P. W. B. Atkins (Eds.), Mindfulness in organizations: Foundations, Reseach and applications (pp. 100-132). Cambridge University Press.

Amaye, A., Neville, K., \& Pope, A. (2016). BigPromises: Using organisational mindfulness to integrate big data in emergency management decision making. Journal of Decision Systems, 25(October), 73-81. https://doi.org/10.1080/12460125.2016.1187419

Ang, J., \& Koh, S. (1997). Exploring the relationships between user information satisfaction and job satisfaction. International Journal of Information Management, 17(3), 169-177. https://doi.org/ 10.1016/S0268-4012(96)00059-X

Ang, J., \& Soh, P. H. (1997). User information satisfaction, job satisfaction and computer background: An exploratory study. Information and Management, 32(5), 255-266. https://doi.org/10.1016/ S0378-7206(97)00030-X

Asyraf, W. M., \& Afthanorhan, B. W. (2013). A comparison of partial least square structural equation modeling (PLS-SEM) and covariance based structural equation modeling (CB-SEM) for confirmatory factor analysis. International Journal of Engineering Science and Innovative Technology (IJESIT), 2(5), 198-205.

Ayyagari, R., Grover, V., \& Purvis, R. (2011). Technostress: Technological antecedents and implications. MIS Quarterly, 35(4), 831.

Bentler, P. M., \& Chou, C. P. (1987). Practical issues in structural modeling. In Sociological methods and research (Vol. 16, issue 1, pp. 78-117). https://doi.org/10.1177/0049124187016001004.

Bernárdez, B., Durán, A., Parejo, J. A., \& Ruiz-Cortés, A. (2018). An experimental replication on the effect of the practice of mindfulness in conceptual modeling performance. Journal of Systems and Software, 136, 153-172. https://doi.org/10.1016/j.jss.2016. 06.104

Bhat, A. (2014). K-Medoids clustering using partitioning around Medoids for performing face recognition. International Journal of Soft Computing, Mathematics and Control (IJSCMC), 3(3), 1-12. https://doi.org/10.14810/ijscmc.2014.3301

Bhattacherjee, A. (2001). Understanding information systems continuance: An expectation-confirmation model. MIS Quarterly, 25(3), 351-370.

Brod, C. (1984). Technostress: The human cost of the computer revolution. Addison-Wesley.

Brown, K. W., \& Ryan, R. M. (2003). The benefits of being present: Mindfulness and its role in psychological well-being. Journal of
Personality and Social Psychology, 84(4), 822-848. https://doi. org/10.1037/0022-3514.84.4.822

Brown, K. W., Ryan, R. M., \& Creswell, J. D. (2007). Mindfulness: Theoretical foundations and evidence for its salutary effects. Psychological Inquiry, 18(4), 211-237. https://doi.org/10.1080/ 10478400701598298

Butler, B. S., \& Gray, P. H. (2006). Reliability, mindfulness and information systems. MIS Quarterly, 30(2), 211-224.

Cammann, C., Fichman, M., Jenkins, D., \& Klesh, J. (1979). The Michigan organizational assessment questionnaire. Ann Arbor. Unpublished Manuscript, University of Michigan. https://www. psc.isr.umich.edu/dis/infoserv/isrpub/pdf/MichiganOrganization alAssessmentPackage_OCR.PDF

Carlo, J. L., Lyytinen, K., \& Boland, R. J. (2012). Dialectis of collective minding: Contradictory appropriations of information technology in a high-risk project. MIS Quarterly, 36(4), 1081-1108.

Carroll, N., \& Conboy, K. (2020). Normalising the "new normal": Changing tech-driven work practices under pandemic time pressure. International Journal of Information Management, 55(July), 102186. https://doi.org/10.1016/j.ijinfomgt.2020. 102186

Carson, S. H., \& Langer, E. J. (2006). Mindfulness and self-acceptance. Journal of Rational - Emotive and Cognitive - Behavior Therapy, 24(1), 29-43. https://doi.org/10.1007/s10942-006-0022-5

Chandra, S., Srivastava, S., \& Shirish, A. (2015). Do technostress creators influence employee innovation? PACIS 2015 Proceedings.

Chaskalson, M., \& Hadley, S. (2015). Mindfulness: historical and contemplative context and recent developments. In J. Reb \& P. W. B. Atkins (Eds.), Mindfulness in Organizations: Foundations, Reseach and Applications (pp. 42-66). Cambridge University Press.

Chen, L., \& Muthitacharoen, A. (2016). An empirical investigation of the consequences of technostress: Evidence from China. Information Resources Management, 29(2), 14-36.

Chiesa, A., \& Serretti, A. (2009). Mindfulness-based stress reduction for stress management in healthy people: a review and metaanalysis. The Journal of Alternative and Complementary Medicine, 15(5), 593-600.

Chiesa, A., \& Serretti, A. (2010). A systematic review of neurobiological and clinical features of mindfulness meditations. Psychological Medicine, 40(8), 1239-1252. https://doi.org/10.1017/S0033 291709991747

Chin, W. (1998). Issues and opinion on structural equation modeling. Management Information Systems Quarterly, 22(1) http://aisel. aisnet.org/misq/vol22/iss $1 / 3$

Choi, E., \& Leroy, H. (2015). Methods of mindfulness: How mindfulness is studied in the workplace. In J. Reb \& P. W. B. Atkins (Eds.), Mindfulness in organizations: Foundations, Reseach and applications (pp. 67-99). Cambridge University Press.

Cohen, J. (1988). Statistical power analysis for the behavioral sciences. In Statistical Power Analysis for the Behavioral Sciences. Routledge. https://doi.org/10.4324/9780203771587

Cooper, C., Dewe, P., \& O'Driscoll, M. (2001). Organizational stress: A review and critique of theory, research, and applications. SAGE publications. https://doi.org/10.4135/9781452231235

Costello, A., \& Osborne, J. (2005). Best practices in exploratory factor analysis: Four recommendations for getting the most from your analysis. Practical Assessment, Research and Evaluation, 10(7), 1-9 https://www.semanticscholar.org/paper/Best-pract ices-in-exploratory-factor-analysis\%3A-four-Costello-Osborne/ d81c1f5a196d33fe734affe285e4f428fd3aea46

Crisci, C., Ghattas, B., \& Perera, G. (2012). A review of supervised machine learning algorithms and their applications to ecological data. Ecological Modelling, 240, 113-122. https://doi.org/10. 1016/j.ecolmodel.2012.03.001 
D’Arcy, J., Gupta, A., \& Tarafdar, M. (2014). Reflecting on the “ dark side " of information technology use. Communications of the Association for Information Systems, 35(July 2014), 109-118.

Dane, E. (2013). Things seen and unseen: Investigating experiencebased qualities of attention in a dynamic work setting. Organization Studies, 34, 45-78. https://doi.org/10.1177/0170840612 464752

DeLone, W. H., \& McLean, E. R. (1992). Information systems success: The quest for the dependent variable. Information Systems Research, 3(1), 60-95. https://doi.org/10.1287/isre.3.1.60

Dernbecher, S., \& Beck, R. (2017). The concept of mindfulness in information systems research: A multi-dimensional analysis. European Journal of Information Systems, 26(2), 121-142. https://doi.org/10.1057/s41303-016-0032-z

Dey, B. L., Al-Karaghouli, W., \& Muhammad, S. S. (2020). Adoption, adaptation, use and impact of information systems during pandemic time and beyond: Research and managerial implications. Information Systems Management, 37(4), 298-302. https://doi. org/10.1080/10580530.2020.1820632

Fieseler, C., Grubenmann, S., Meckel, M., \& Muller, S. (2014). The leadership dimension of coping with technostress. In Proceedings of the annual Hawaii international conference on system sciences (pp. 530-539). https://doi.org/10.1109/HICSS.2014.73

Fischer, T., \& Riedl, R. (2017). Technostress research: A nurturing ground for measurement pluralism? Communications of the Association for Information Systems, 40(1), 375-401.

Fischer, T., \& Riedl, R. (2019). Is the technostress creators inventory still an up-to-date measurement instrument? Results of a largescale interview study medical statistics view project technostress in organizations view project. 14th International Conference on Wirtschaftsinformatik, February. https://www.researchgate.net/ publication/331198725

Fornell, C., \& Larcker, D. F. (1981). Structural equation models with unobservable variables and measurement error: Algebra and statistics. Journal of Marketing Research, 18(3), 382-388. https:// doi.org/10.1177/002224378101800313

Fuglseth, A. M., \& Sørebø, Ø. (2014). The effects of technostress within the context of employee use of ICT. Computers in Human Behavior, 40, 161-170. https://doi.org/10.1016/j.chb.2014.07. 040

Glomb, T. M., Duffy, M. K., Bono, J. E., \& Yang, T. (2011). Mindfulness at work. Research in Personnel and Human Resources Management, 30, 115-157. https://doi.org/10.1108/S07427301(2011)0000030005

Good, D. J., Lyddy, C. J., Glomb, T. M., Bono, J. E., Brown, K. W., Duffy, M. K., Baer, R. A., Brewer, J. A., \& Lazar, S. W. (2016). Contemplating mindfulness at work: An integrative review. Journal of Management, 42(1), 114-142. https://doi.org/10.1177/ 0149206315617003

Grégoire, S., \& Lachance, L. (2015). Evaluation of a brief mindfulness-based intervention to reduce psychological distress in the workplace. Mindfulness, 6(4), 836-847. https://doi.org/10.1007/ s12671-014-0328-9

Grover, S. L., Teo, S. T. T., Pick, D., \& Roche, M. (2016). Mindfulness as a personal resource to reduce work stress in the job demandsresources model. Stress and Health, November. https://doi.org/ 10.1002/smi.2726

Hadidi, R., \& Carter, L. (2016). Exploring the impact of IT mindfulness on E- government affordances: An exploratory study. SIGHCI, 2016, 1-5.

Hair, J. F., Black, W., Babin, B., Anderson, R., \& Tatham, R. (2010). Multivariate data analysis (6th ed.) Pearson Prentice Hall.

Hou, C.-K. (2012). Examining the effect of user satisfaction on system usage and individual performance with business intelligence systems: An empirical study of Taiwan's electronics industry.
International Journal of Information Management, 32(6), 560 573. https://doi.org/10.1016/j.ijinfomgt.2012.03.001

Hsu, L. L., Lai, R. S. Q., \& Weng, Y. T. (2008). Understanding the critical factors effect user satisfaction and impact of ERP through innovation of diffusion theory. International Journal of Technology Management, 43(1/2/3), 30-47. https://doi.org/10.1504/ IJTM.2008.019405

Huling, B. (2020). Better Functioning Tech Makes for Less Stress at Work I Dell Technologies. https://www. dellt echnologies.com/en-us/blog/blog-better-funct ioning-tech-makes-for-less-stress-at-work/

Hülsheger, U. R., Alberts, H. J. E. M., Feinholdt, A., \& Lang, J. W. B. (2012). Benefits of mindfulness at work: The role of mindfulness in emotion regulation, emotional exhaustion, and job satisfaction. Journal of Applied Psychology, 98(2), 310-325. https://doi.org/ 10.1037/a0031313

Hung, W.-H., Chang, L.-M., \& Lin, C.-H. (2011). Managing The Risk Of Overusing Mobile Phones In The Working Environment: A Study Of Ubiquitous Technostress. Pacis 2011 Proceedings, 81.

Hyland, P. K., Lee, R. A., \& Mills, M. J. (2015). Mindfulness at work: A new approach to improving individual and organizational performance. Industrial and Organizational Psychology, 1-27. https://doi.org/10.1017/iop.2015.41

Ioannou, A., \& Papazafeiropoulou, A. (2017). Using IT mindfulness to mitigate the negative consequences of technostress. AMCIS 2017 Proceedings.

Ioannou, A., Tussyadiah, I., \& Marshan, A. (2021). Dispositional mindfulness as an antecedent of privacy concerns: A protection motivation theory perspective. Psychology and Marketing, 38(10), 1766-1778. https://doi.org/10.1002/mar.21529

Jacobs, S. J., \& Blustein, D. L. (2008). Mindfulness as a coping mechanism for employment uncertainty. The Career Development Quarterly, 57(2), 174-180. https://doi.org/10.1109/EMR.2010. 5645752

Jena, R. K. (2015). Technostress in ICT enabled collaborative learning environment: An empirical study among Indian academician. Computers in Human Behavior, 51, 1116-1123. https://doi.org/ 10.1016/j.chb.2015.03.020

Jensen, M. L., Dinger, M., Wright, R. T., \& Thatcher, J. B. (2017). Training to mitigate phishing attacks using mindfulness techniques. Journal of Management Information Systems, 34(2), 597-626. https://doi.org/10.1080/07421222.2017.1334499

Khan, A., \& Rehman, H. (2013). An empirical analysis of correlation between technostress and job satisfaction: A case of KPK, Pakistan. Pakistan Journal of Library \& Information Science, 14, 9-15.

Khan, A., Nawaz, M. M., Aleem, M., \& Hamed, W. (2012). Impact of job satisfaction on employee performance: An empirical study of autonomous medical institutions of Pakistan. African Journal of Business Management, 6(7), 2697-2705. https://doi.org/10. 5897/AJBM11.2222

Kiken, L. G., \& Shook, N. J. (2012). Mindfulness and emotional distress: The role of negatively biased cognition. Personality and Individual Differences, 52(3), 329-333. https://doi.org/10.1016/j. paid.2011.10.031

Kodinariya, T. M., \& Makwana, P. R. (2013). Review on determining number of cluster in K-means clustering. International Journal of Advance Research in Computer Science and Management Studies, 1(6), 2321-7782.

Kolkur, S., \& Kalbande, D. R. (2016). Review of machine learning algorithms in R software for diagnosis of ESD diseases. In Proceedings of the ACM symposium on women in research 2016 WIR '16, 20-25. https://doi.org/10.1145/2909067.2909101

Kumar, R., Lal, R., Bansal, Y., \& Sharma, S. K. (2013). Technostress in relation to job satisfaction and Organisational commitment 
among IT professionals. International Journal of Scientific and Research Publications, 3(12), 12-14.

Kursa, M. B., \& Rudnicki, W. R. (2010). Feature selection with the Boruta package. Journal Of Statistical Software, 36(11), 1-13.

Langer, E. J. (1989). Mindfulness. Addison-Wesley/Addison Wesley Longman.

Langer, E. J. (1992). Matters of mind: Mindfulness/mindlessness in perspective. Consciousness and Cognition, 1(3), 289-305. https://doi.org/10.1016/1053-8100(92)90066-J

Langer, E. J. (2000). Mindful Learning., 9(6), 220-223.

Langer, E. J., \& Moldoveanu, M. (2000). The construct of mindfulness. Journal of Social Issues, 56(1), 1-9. https://doi.org/10. 1111/0022-4537.00148

Lanjewar, R., \& Yadav, O. P. (2013). Understanding of customer profiling and segmentation using K-means clustering method for Raipur Sahkari Dugdh Sangh Milk products. International Journal of Research in Computer and Communication Technology, 2(3), 103-107.

Lazarus, R. (1966). Psychological stress and the coping process. McGraw-Hill https://psycnet.apa.org/record/1966-35050-000

Lazarus, R., \& Folkman, S. (1984). Stress, appraisal, and coping (New York Springer (ed.)). https://www.scirp.org/(S(czeh2tfqyw2orz5 53k1w0r45))/reference/ReferencesPapers.aspx?ReferenceID= 1927117

Lee, A. R., Son, S.-M., \& Kim, K. K. (2016). Information and communication technology overload and social networking service fatigue: A stress perspective. Computers in Human Behavior, 55, 51-61. https://doi.org/10.1016/j.chb.2015.08.011

Levy, D. M., Wobbrock, J. O., Kaszniak, A. W., \& Ostergren, M. (2012). The effects of mindfulness meditation training on multitasking in a high-stress information environment. Graphics Interface, 2012, 45-52. https://doi.org/10.1145/1979742.1979862

Li, Z., Wang, G., \& He, G. (2017). Milling tool wear state recognition based on partitioning around medoids (PAM) clustering. The International Journal of Advanced Manufacturing Technology, $88(5-8), 1203-1213$.

Liang, H., \& Xue, Y. (2009). Avoidance of information technology threats: A theoretical perspective. MIS Quarterly, 33(1), 71-90. https://doi.org/10.2307/20650279

Little, T. D., Cunningham, W. A., Shahar, G., \& Widaman, K. F. (2002). To parcel or not to parcel: Exploring the question, weighing the merits. Structural equation modeling, 9(2), 151-173.

Maier, C., Laumer, S., Wirth, J., \& Weitzel, T. (2017). Personality and technostress: Theorizing the influence of IT mindfulness. In ICIS 2017 Proceedings (pp. 1-11).

Maier, C., Laumer, S., Wirth, J., \& Weitzel, T. (2019). Technostress and the hierarchical levels of personality: a two-wave study with multiple data samples. European Journal of Information Systems, 28(5), 496-522. https://doi.org/10.1080/0960085X.2019. 1614739

MAPPG. (2015). Mindful nation UK. In The Mindfulness All-Party Parlamentary Group (Issue October). http://www.themindful nessinitiative.org.uk/images/reports/Mindfulness-APPG-Report_ Mindful-Nation-UK_Oct2015.pdf

Marsh, H. W., \& Hocevar, D. (1985). Application of confirmatory factor analysis to the study of self-concept: First- and higher order factor models and their invariance across groups. Psychological Bulletin, 97(3), 562-582. https://doi.org/10.1037/0033-2909.97.3.562

Mesmer-Magnus, J., Manapragada, A., Viswesvaran, C., \& Allen, J. W. (2017). Trait mindfulness at work: A meta-analysis of the personal and professional correlates of trait mindfulness. Human Performance, 30(2-3). https://doi.org/10.1080/08959285.2017. 1307842

Molino, M., Ingusci, E., Signore, F., Manuti, A., Giancaspro, M. L., Russo, V., Zito, M., \& Cortese, C. G. (2020). Wellbeing costs of technology use during Covid-19 remote working: An investigation using the Italian translation of the technostress creators scale. Sustainability, 12(15), 1-20. https://doi.org/10.3390/ SU12155911

Nojoumi, A. R., Givehchi, S., \& Mahmoodzadeh, A. (2015). Crisis management arising from technological risks and its models in south pars: A systematic review. Journal of Materials and Environmental Science, 6(7), 1965-1974.

Nunnally, J. C. (1978). Psychometric theory. McGraw-Hill.

Othata, P., \& Pantaragphong, P. (2017). Number of cluster for k-means clustering by RCFDC. In The 22nd Annual Meeting in Mathematics (AMM 2017), Amm, 1-8.

Paasonen, S. (2015). As networks fail: Affect, technology, and the notion of the user. Television and New Media, 16(8), 701-716. https://doi.org/10.1177/1527476414552906

Pearson, M. R., Brown, D. B., Bravo, A. J., \& Witkiewitz, K. (2015). Staying in the moment and finding purpose: The associations of trait mindfulness, decentering, and purpose in life with depressive symptoms, anxiety symptoms, and alcohol-related problems. Mindfulness, 6(3), 645-653. https://doi.org/10.1007/ s12671-014-0300-8

Pflügner, K., Maier, C., \& Weitzel, T. (2021). The direct and indirect influence of mindfulness on techno-stressors and job burnout: A quantitative study of white-collar workers. Computers in Human Behavior, 115, 106566. https://doi.org/10.1016/j.chb. 2020.106566

Podsakoff, P. M., MacKenzie, S. B., Lee, J. Y., \& Podsakoff, N. P. (2003). Common method biases in behavioral research: A critical review of the literature and recommended remedies. Journal of Applied Psychology, 88(5), 879-903. https://doi.org/10.1037/ 0021-9010.88.5.879

Prasad, K., Vaidya, R. W., \& Mangipudi, M. R. (2020). Effect of occupational stress and remote working on psychological well-being of employees: An empirical analysis during covid-19 pandemic concerning information technology industry in Hyderabad. Indian Journal of Commerce \& Management Studies, 11(2), 1-13. https://doi.org/10.18843/ijcms/v11i2/01

Quaglia, J. T., Braun, S. E., Freeman, S. P., Mcdaniel, M. A., Brown, K. W., Quaglia, J. T., Braun, S. E., Freeman, S. P., Mcdaniel, M. A., \& Brown, K. W. (2016). Meta-analytic evidence for effects of mindfulness training on dimensions of self-reported dispositional mindfulness. Psychological Assessment, 28(7), 803-818. https:// doi.org/10.1037/pas0000268

Ragu-Nathan, T. S., Tarafdar, M., Ragu-Nathan, B. S., \& Tu, Q. (2008). The consequences of technostress for end users in organizations: Conceptual development and empirical validation. Information Systems Research, 19(4), 417-433. https://doi.org/10.1287/isre. 1070.0165

Ramiller, N., \& Swanson, B. (2009). Mindfulness routines for innovating with information technology. Journal of Decision Systems, 18(1), 13-26. https://doi.org/10.3166/jds.18.13-26

Reb, J., Narayanan, J., \& Ho, Z. W. (2015). Mindfulness at work: Antecedents and consequences of employee awareness and absentmindedness. Mindfulness, 6(1), 111-122. https://doi.org/10. 1007/s12671-013-0236-4

Riedl, R., Kindermann, H., Auinger, A., \& Javor, A. (2012). Technostress from a neurobiological perspective: System breakdown increases the stress hormone cortisol in computer users. Business and Information Systems Engineering, 4(2), 61-69. https://doi. org/10.1007/s12599-012-0207-7

Roberts, N., Thatcher, J., \& Klein, R. (2007a). Tying context to postadoption behavior with information technology: A conceptual and operational definition of mindfulness. In AMCIS 2007 Proceedings, Paper 450.

Roberts, N., Thatcher, J., \& Klein, R. (2007b). Using information technology mindfully. In Proceedings of the 2007 Southern Association for Information Systems Conference (pp. 3-4). 
Salisbury, W., Chin, W., \& Gopal, A. (2002). Better theory through measurement-Developing a scale to capture consensus on appropriation. Information Systems Research, 13(1), 91-103.

Schreiber, J. B., Stage, F. K., King, J., Nora, A., \& Barlow, E. A. (2006). Reporting structural equation modeling and confirmatory factor analysis results: A review. Journal of Educational Research, 99(6), 323-337. https://doi.org/10.3200/JOER.99.6. 323-338

Schultz, P. P., Ryan, R. M., Niemiec, C. P., Legate, N., \& Williams, G. C. (2015). Mindfulness, work climate, and psychological need satisfaction in employee well-being. Mindfulness, 6(5), 971-985. https://doi.org/10.1007/s12671-014-0338-7

Shapiro, S., Wang, M., \& Peltason, E. (2015). What is mindfulness, and why should organizations care about it? In J. Reb \& P. W. B. Atkins (Eds.), Mindfulness in organizations: Foundations, Reseach and applications (pp. 17-41). Cambridge University Press.

Shonin, E., \& Van Gordon, W. (2015). Managers' experiences of meditation awareness training. Mindfulness, 6(4), 899-909. https:// doi.org/10.1007/s12671-014-0334-y

Shonin, E., Van Gordon, W., \& Griffiths, M. D. (2014). The treatment of Workaholism with meditation awareness training: A case study. EXPLORE: The Journal of Science and Healing, 10(3), 193-195. https://doi.org/10.1016/j.explore.2014.02.004

Smith, G. T., Combs, J. L., \& Pearson, C. M. (2012). Brief instruments and short forms. In APA handbook of research methods in psychology, Vol 1: Foundations, planning, measures, and psychometrics (pp. 395-409). American Psychological Association. https://doi.org/10.1037/13619-021

Stich, J.-F., Tarafdar, M., Stacey, P., \& Cooper, C. L. (2019). E-mail load, workload stress and desired e-mail load: a cybernetic approach. Information Technology \& People, 32(2), 430-452. https://doi.org/10.1108/ITP-10-2017-0321

Sun, H. (2011). Making sound adoption decisions: A longitudinal study of mindfulness in technology adoption and continued use. In Thirty second international conference on information systems 2011, 3 (pp. 1812-1829).

Sun, H., Fang, Y., Kong, H., \& Kong, H. (2016). Choosing a fit technology: Understanding mindfulness in technology adoption and continuance. Journal of the Association for Information Systems, 17(6), 377-412.

Tahir Iqbal, M., Latif, W., \& Naseer, W. (2012). The impact of person job fit on job satisfaction and its subsequent impact on employees performance. Mediterranean Journal of Social Sciences, 3(2), 523-530. https://doi.org/10.5901/mjss.2012.v3n2.523

Tarafdar, M., Tu, Q., Ragu-Nathan, B., \& Ragu-Nathan, T. (2007). The impact of technostress on role stress and productivity. Journal of Management Information Systems, 24(1), 301-328. https://doi. org/10.2753/MIS0742-1222240109

Tarafdar, M., Tu, Q., \& Ragu-Nathan, T. S. (2010). Impact of technostress on end-user satisfaction and performance. Journal of Management Information Systems, 27(3), 303-334. https://doi. org/10.2753/MIS0742-1222270311

Tarafdar, M., Tu, Q., Ragu-Nathan, T. S., \& Ragu-Nathan, B. S. (2011). Crossing to the dark side: Examining creators, outcomes, and inhibitors of technostress. Communications of the ACM, 54(9), 113. https://doi.org/10.1145/1995376.1995403

Tarafdar, M., Gupta, A., \& Turel, O. (2013). The dark side of information technology use. Information Systems Journal, 23(3), 269-275. https://doi.org/10.1111/isj.12015

Tarafdar, M., Pullins, E. B., \& Ragu-Nathan, T. S. (2015). Technostress: Negative effect on performance and possible mitigations. Information Systems Journal, 25(2), 103-132. https://doi.org/ 10.1111/isj.12042
Tarafdar, M., Cooper, C. L., \& Stich, J. F. (2017). The technostress trifecta - techno eustress, techno distress and design: Theoretical directions and an agenda for research (pp. 1-37). Information Systems Journal. https://doi.org/10.1111/isj.12169

Teo, T. S. H., Srivastava, S. C., Ranganathan, C., \& Loo, J. W. K. (2011). A framework for stakeholder oriented mindfulness: Case of RFID implementation at YCH group, Singapore. European Journal of Information Systems, 20(2), 201-220. https://doi.org/ 10.1057/ejis.2010.58

Thatcher, J., Wright, R. T., Zagenczyk, T. J., Klein, R., \& Sun, H. (2018). Mindfulness in information technology use: Definitions, distinctions, and a new measure. MIS Quarterly, 42(3), 831-847. https://doi.org/10.25300/misq/2018/11881

Thatcher, J., Wright, R., Sun, H., Zagenczyck, T., \& Klein, R. (n.d.). Mindfulness in information technology use: Definitions, distinctions, and a new measure. MIS Quarterly.

Van Gordon, W., Shonin, E., Zangeneh, M., \& Griffiths, M. D. (2014). Work-related mental health and job performance: Can mindfulness help? International Journal of Mental Health and Addiction, 12(2), 129-137. https://doi.org/10.1007/s11469-014-9484-3

Virgili, M. (2015). Mindfulness-based interventions reduce psychological distress in working adults: a Meta-analysis of intervention studies. Mindfulness, 6(2), 326-337. https://doi.org/10.1007/ s12671-013-0264-0

Voci, A., Veneziani, C. A., \& Metta, M. (2016). Affective organizational commitment and dispositional mindfulness as correlates of burnout in health care professionals. Journal of Workplace Behavioral Health, 31(2), 63-70. https://doi.org/10.1080/15555 240.2015.1047500

Weil, M., \& Rosen, L. (1997).Technostress: Coping with technology@ work@home@play.Wiley.

Weinert, C. (2018). Coping with discrepant information technology events: A literature review. Research Papers. https://aisel.aisnet. org/ecis2018_rp/137

Weinstein, N., Brown, K. W., \& Ryan, R. M. (2009). A multi-method examination of the effects of mindfulness on stress attribution, coping, and emotional well-being. Journal of Research in Personality, 43(3), 374-385. https://doi.org/10.1016/j.jrp.2008.12. 008

Wolf, M., Pinter, T., \& Beck, R. (2011). Individual mindfulness and it systems use - mitigating negative consequences of information overload. ECIS, 2011, 1-13.

Yan, Z., Guo, X., Lee, M., \& Vogel, D. (2013). A conceptual model of technology features and technostress in telemedicine communication. Information Technology \& People, 26(3), 283-297.

Zadeh, R., Faraahi, A., \& Mastali, A. (2011). Profiling bank customers behaviour using cluster analysis for profitability. In International conference on industrial engineering and operations management (pp. 458-467).

Zimmaro, L. A., Salmon, P., Naidu, H., Rowe, J., Phillips, K., Rebholz, W. N., Giese-Davis, J., Cash, E., Dreeben, S. J., BayleyVeloso, R., Jablonski, M. E., Hicks, A., Siwik, C., \& Sephton, S. E. (2016). Association of Dispositional Mindfulness with stress, cortisol, and well-being Among University undergraduate students. Mindfulness, 874-885. https://doi.org/10.1007/ s12671-016-0526-8

Zou, H. M., Sun, H., \& Fang, Y. (2015). Understanding post-adoption regret from the perspectives of herding and mindfulness. In Thirty sixth international conference for information systems (pp. 1-19).

Publisher's Note Springer Nature remains neutral with regard to jurisdictional claims in published maps and institutional affiliations. 